DIVISION OF THE HUMANITIES AND SOCIAL SCIENCES

CALIFORNIA INSTITUTE OF TECHNOLOGY

PASADENA, CALIFORNIA 91125

EXPERIMENTAL TESTBEDDING OF A POLLUTION TRADING

SYSTEM: SOUTHERN CALIFORNIA'S RECLAIM EMMISSIONS MARKET

Takashi Ishikida

Net Exchange Corporation

John O. Ledyard

California Institute of Technology

Mark Olson

University of Arizona

David Porter

University of Arizona

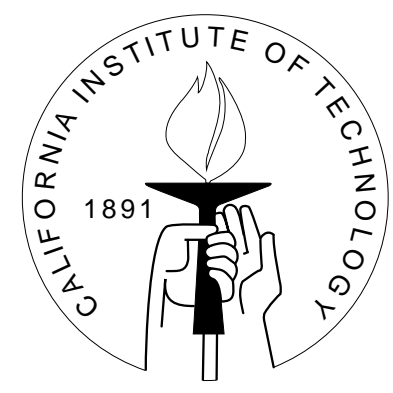

SOCIAL SCIENCE WORKING PAPER 1094 


\section{Experimental Testbedding of a Pollution Trading System: Southern California's RECLAIM Emissions Market}

\section{Introduction}

The efficient management of air quality through the use of pollution emissions trading systems is not a new idea (see Montgomery (1972)). It is well known, theoretically, that one can achieve an efficient allocation of abatement among many firms by establishing an appropriate structure of pollution rights, if trade occurs so that a competitive equilibrium is achieved. However, the implementation of such systems is new and it appears, in many cases, that the efficiency gains promised by the theorists are foregone because the implemented market design is not up to the challenge. See, for example, Atkinson and Tietenberg (1991), Burtaw (1994), Hahn and Hester (1989), and Joskow, Schmalensee and Bailey(1999). Even under the best of situations, emission trading markets are very thin. Because most trades are bilateral, with few known alternatives, price-taking behavior is not incentive compatible. Because firms need to complete trades

only occasionally, ${ }^{1}$ price discovery is difficult if not impossible. Traditional markets, broker-dealer systems, or traditional auctions simply do not provide the information and incentives needed to guide traders to a competitive equilibrium. Gains from exchange often go unrealized.

In the early 90's a new emission trading program was created by the South Coast Air Quality Management District (SCAQMD), the agency charged with pollution control in the geographical area around Los Angeles. Environmentalists, polluting firms, and others supported it as the only apparent solution to a situation of escalating compliance and abatement costs. It was believed and hoped that a trading program would produce significant cost-savings for firms over the existing command-control approach. The program is called the REgional CLean Air Incentives Market (RECLAIM) and it allocates permits to facilities and allows trade. But, rather than having one market for one universal permit, in order to retain some measure of regulatory control, the 
SCAQMD created 136 different permits. They created a different permit for each of two pollutants (nitrogen and sulfur oxides -- NOx and SOx) to better control each, for each of two land zones (upwind and downwind) to better control the distribution of the pollutants, for each of 17 separate years from 1994 to 2010 with possible continuation beyond) to better control the distribution of pollution over time, and for each of two compliance cycles to better control year end price volatility. ${ }^{2}$ In total, there are 136 different permits that firms must consider as they attempt to minimize their costs of compliance. This means that there are 136 markets for pollution permits in the RECLAIM program. The complexity associated with such an interdependent system of commodities makes trading by traditional methods extremely difficult. Emission trading in LA is more like multi-lateral bargaining than competitive markets. The benefits to be harvested from the RECLAIM program in reduced compliance costs could easily remain unrealized. Participants in the program recognized this almost immediately. ${ }^{3}$ In response, they requested a new trading system be developed, one that provided some help and guidance through the complexities.

We took up the challenge knowing that theory and current practice provided little guidance for a good market design. It was natural, therefore, to turn to the experimental economics methodology of testbedding for help. Testbedding new systems as a systematic part of a design process is standard fare in engineering but only recently has it been applied to economics. (See Banks, et.al. (1989) or Plott(1994)). Unlike experiments designed to test specific theories of behavior, testbedding is used when theory supplies little design advice. It helps eliminate bad design features with unintended consequences and it provides a reality check for intuition.

\footnotetext{
${ }^{1}$ In Los Angeles, compliance is monitored only quarterly.

${ }^{2}$ The two cycles are January through December and July through June. (See Carlson et al. (1993) for a discussion of the price volatility problem).

${ }^{3}$ They also recognized that traditional trading methods placed them in a very weak strategic position relative to brokers who were certainly prepared to capture most of the realized gains from trade for themselves.
} 
Here, we report on some experiments used to guide our design of the Automated Credit Exchange (ACE) trading system - our solution to the lack of liquidity. ${ }^{4}$ The paper is organized as follows. In Sections II and III, we briefly describe the RECLAIM program as well as other programs and markets. We then describe, in Section IV, the testbed results for a standard market design; the Uniform Price Double Auction (UPDA). That design was found wanting. In Section V, we describe the details of our design for ACE and, in Section VI, we present some of the experimental evidence that gave us confidence to put ACE into competition with brokers as a process for trading in the RECLAIM program. ACE has been operating successfully and quarterly since April 1995 over the Internet. ${ }^{5}$

\section{Brief Description of the RECLAIM Program}

On October 15, 1993, RECLAIM was put in place. It defined a set of market-based incentive rules that mandated reductions in emissions of nitrogen oxide (NOx) and sulfur oxide (SOx) by imposing factory mass emissions caps. Under RECLAIM, a manufacturer is given an annual emissions limit for his entire plant, and yearly reductions to the plantwide limit. Specifically, all sources at a particular facility are collectively assigned an annual emissions cap based on historic rates for a selected three-year period. The cap defines the amount of emissions the facility is allowed for the year. The cap declines annually (8.3\% per year on average for NOx and 6.8\% per year on average for SOx) from 1994 to 2003 and then levels off through 2010. The program applies to the largest emission sources for these pollutants in the LA Basin.

Facilities are allowed to emit pollutants up to the amount of RECLAIM Trading Credits (RTCs) they possess. A facility emitting less than its allocation cap is permitted to sell its excess emissions to other facilities in the form of RTCs. If a factory finds that it will emit, or has emitted, more than its cap, it may purchase RTCs from other facilities or make reductions in emissions by installing control equipment or reducing production.

\footnotetext{
${ }^{4}$ As one will see later, ACE is a computer assisted call market based on the principle of combined value trading.

${ }^{5}$ A paper reporting on the actual performance of ACE is being prepared.
} 
To retain some semblance of regulatory control, an RTC is designated by the year, compliance cycle, the pollutant (NOx or SOx), and its zone. The first compliance cycle runs from January 1 to December 31 of each year and the second cycle runs from June 1 to July 31 of each year. Zones refer to LA Basin geography and prevailing onshore winds. The zones restrict transfers so that upwind (coastal) sources cannot use purchased downwind (inland) RTCs. Each RTC is only valid for the single year, cycle, and zone for which it is designated. Banking is not allowed.

RECLAIM did not establish or specify a mechanism for the trading of RTCs; it only established a marketable asset or property right. It left the creation and operation of markets, broker mechanisms, etc. to the private sector. But that created an impossible task for those responsible for finding profitable trades. Even without markets, a firm's environmental engineer has a complex financial problem. A decision must be made whether to purchase abatement equipment, whether to buy or sell permits, and which of the 136 permits to trade. There are innumerable options and tradeoffs. And the answer depends critically on the prices of the permits.

For example, a firm's production plans might require it to emit 1 million pounds of NOx per year for 5 years using current technology. If the firm has an 800,000 pound cap on NOx emissions, it will not be able to meet its production goals and stay within its environmental constraints. To meet these goals the firm may have a number of options including:

-[ Purchase pollution abatement equipment for $\$ 1$ million that will reduce 200,000 pounds of NOx per year.

- 4 Purchase 200,000 RTCs for each of the 5 years, or

- 0 Purchase 100,000 RTCs for each of the 5 years and purchase pollution abatement equipment for $\$ 600,000$ that will reduce 100,000 pounds of NOx per year, or

- $\square$ Buy current year RTCs, delay installation of abatement equipment for 2 years, and sell future RTCs.

The option that is most cost effective for the firm will depend on the prices of the component RTCs. Further, to avoid market risk the firm would like to be able to 
purchase 5 years' of RTCs as one package. If the firm were to purchase the first year credits and then find that unanticipated movements in the prices of the last year credits caused the package price to exceed the cost of the investment in equipment, the firm could easily find that it had not acted in its most cost-effective way. It could also then be held up.

In RECLAIM, such a financial calculation is daunting. There are 136 different RTC's to choose from. In the above example, suppose the engineer is located near the ocean. Suppose 100,000 pounds of N0x pollution must be covered in the last half of 1998 . Suppose further that she can use either 100,000 of 1998 cycle 1, zone 1 NOx or 100,000 of 1998 cycle 2 , zone 1 NOx or some combination of those. She cannot buy zone 2 permits; that is, permits from inland factories. But if she wants to add abatement equipment and sell permits she holds, she can sell them to anyone located either coastal or inland. And she must remember that the supply of, say, 2002 permits is much lower than those for 1999 and that this should lead to expectations of higher prices for permits for later years. Finding the least cost solution to the engineer's problem would be difficult even if all price information were available and she could go to competitive markets to buy or sell.

In the RECLAIM world such active, competitive markets simply don't, and probably never will, exist. They are too thin.. This leaves the environmental engineer, and the company $\mathrm{CFO}$, with a very complex bargaining problem. For example, how would one engineer decide on the maximum price she would be willing to pay for a pound of 1999, cycle 2, zone 1 NOx since that obviously depends on the price she will have to pay for 2002, cycle 1, zone 2 NOx. Multi-lateral bargaining over 136 dimensions with complex constraints simply can't be done efficiently using traditional broker methods.

Thus, in 1993, many of the firms in the program requested the design of a new type of market that would help them with their problems. To respond, we looked first, unsuccessfully, to other emissions markets. We then tried a well-known, standard call market design, UPDA. It too could not handle our problem. So we created a combined 
value call market. Throughout this process, we relied heavily on the new methodology of economic testbedding. How we did this is described next.

\section{Previous Emissions Markets}

We first looked to existing market designs as possibilities for RECLAIM.

The predecessor of RECLAIM was the Emission Reduction Credit Market (ERC). This program involves limited trading of credits that are generated when facilities shut down, retrofit or can show real sustained emission reductions from their source. This was a broker market with sequential bilateral trading. However, sequential and bilateral ERC trades between noncontiguous sources implies that air quality increases in one location and decreases in the other which can violate standards imposed by State Implementation Plans. In order to obtain a true market equilibrium, simultaneous trading of permits by "all" firms that takes into account local ambient standards is required. The ERC market was not designed in this manner. Significantly large transaction costs in searching for sellers and in ensuring the feasibility of an ERC trade have resulted in large commission fees and few trades (see Atkinson and Tietenberg (1991)).

The most successful emission trading market to date has been the EPA's $\mathrm{SO}_{2}$ allowance market. [See Burtaw (1994) or Cason (1995).] In Title IV of the Clean Air Act Amendments of 1990, U.S. electric utilities were required to reduce sulfur dioxide $\left(\mathrm{SO}_{2}\right)$ emissions by approximately ten million tons from 1980 levels. The Amendments specify annual caps on total $\mathrm{SO}_{2}$ emissions with each regulated utility receiving an allocation of $\mathrm{SO}_{2}$ allowances each year. ${ }^{6}$ The Amendments also allowed for creation of markets to buy and sell allowances. The allowances are bankable so that unused allowances can be carried forward to future years. Thus this really is one market and not many. However, the EPA auction designed for the $\mathrm{SO}_{2}$ allowance trading has some poor incentive properties for the bidders. Cason and Plott (1996) show that the EPA's allowance auction

\footnotetext{
${ }^{6}$ The allocations were partially based on past emission levels and "political considerations." In addition, the EPA retained a small fraction of allowances that it sold in special auctions and direct sales.
} 
causes participants to strategically underreveal willingness-to-pay and willingness-to-sell. Joskow et al. (1999) have recently questioned the experimental and theoretical results of Cason (1993) and Cason and Plott (1996). Their argument is that the private markets, in $\mathrm{SO}_{2}$ allowances, provide participants in the EPA auction with information about the marginal value of allowances. In addition, they suggest that empirical results from the auction do not support a cost underrevalation by sellers. Nonetheless, Joskow et al. (1999) do acknowledge that the $\mathrm{SO}_{2}$ markets are far from the idealized frictionless transmitters of information given the uncertainty and long-term nature of abatement investments.

The argument over the performance of the $\mathrm{SO}_{2}$ market is not the focus of this paper. RECLAIM is. The RECLAIM program differs significantly from the $\mathrm{SO}_{2}$. First, allowances in RECLAIM are designated by areas so that some trading of credits from one area to another is not allowed. Second, there is no banking of credits in RECLAIM. Lastly, RECLAIM credits are also designated by compliance cycles and these cycles overlap.

So neither existing design was of much relevance for our problems. We had to create a new system.

\section{Would a Standard Auction Market Work?}

The basic economic features of RECLAIM are: (1) the program has very few participants (there are 390 NOx-producing facilities and 41 SOx-producing facilities, but only a handful were committed to market participation.); (2) there is no established trading history so that price discovery was not going to be a low cost activity; (3) there is a need to trade only at quarterly intervals when compliance checks are reported; and (4) buyers and sellers would prefer to buy or sell entire portfolios of credits to avoid market transaction risk - the undesired movement of prices as one is trading from one portfolio position to another. 
These features of the economic environment describe what financial economists would call a thin market. Thin markets create problems for standard broker-dealer markets because the thinness results in larger bid-ask spreads and poorer price discovery properties (see Campbell et al (1991)). One known solution to disorderly price discovery, when markets are thin, is to allow order aggregation through call markets. This leads to better price discovery and reduced price volatility. (See McCabe et al. (1992)).

In a call market, exchanges occur at the same time with feedback so that all markets clear simultaneously. ${ }^{7}$ In what follows we will describe two types of call auctions one might imagine using to trade RTCs. One design treats each commodity separately and has a single uniform price for each RTC. The other design allows for combined value orders and tries to preserve the uniform price structure when possible but allows for non-linear pricing if necessary to encourage more gains from trade.

Each of the call markets was implemented as a sequential process. This allows a modicum of negotiation on the way to the real call. Specifically, the markets are not oneshot. Over a series of rounds traders can update bids and offers based on previous iteration results. This feature has been shown to be important in price discovery (see McCabe et al. (1992) and Banks et al. (1989)). In each round, bids and offers must be improvements. To provide proper incentives for price discovery, a new bid, in order to be accepted, must improve on current bids (increase bid price) or offers (reduce offer price). Rejected bids are discarded after each iteration. Finally, in each call market design, prices are calculated from marginal trades. Thus, infra-marginal bids and offers have an incentive to reveal.

\footnotetext{
${ }^{7}$ Allowing markets to clear simultaneously has been shown to be an important feature in other auctions. For example, in the US FCC spectrum auctions, the major design feature is that all the licenses within a band are auctioned simultaneously, so that bidders will be able to know their substitution possibilities (see Milgrom (1997)).
} 
Let us look at a standard type of call market, UPDA--the Uniform Price Double Auction (see Smith (1982), Van Boening (1996) and Davis and Holt (1993)). In this design each buyer i submits a set of bids for each commodity $\mathrm{j}$ of the form:

$<\left(\mathrm{p}_{\mathrm{ij}}{ }^{1}, \mathrm{Q}_{\mathrm{ij}}{ }^{1}\right), \ldots . .,\left(\mathrm{p}_{\mathrm{ij}}{ }^{\mathrm{m}}, \mathrm{Q}_{\mathrm{ij}}{ }^{\mathrm{m}}\right)>\quad=\mathrm{B}_{\mathrm{ij}}$

where $\mathrm{p}_{\mathrm{ij}}{ }^{\mathrm{w}}$ denotes the per unit bid price in order w by buyer $\mathrm{i}$ for commodity $\mathrm{j}$ and $\mathrm{Q}_{\mathrm{ij}}{ }^{\mathrm{w}}$ is the corresponding maximum quantity demanded ${ }^{8}$ Each seller $\mathrm{k}$ submits offers of the form:

$<\left(c_{k j}{ }^{1}, S_{k j}{ }^{1}\right), \ldots .,\left(c_{k j}{ }^{n}, S_{k j}{ }^{n}\right)>\quad=O_{k j}$

where $c_{k j}{ }^{v}$ denotes the per unit offer price in order $v$ by seller $k$ for commodity $j$ and $S_{k j}{ }^{v}$ is the corresponding maximum quantity offered. Let $\mathrm{P}_{\mathrm{ij}}{ }^{\mathrm{w}}=\mathrm{p}_{\mathrm{ij}}{ }^{\mathrm{W}} \bullet \mathrm{Q}_{\mathrm{ij}}{ }^{\mathrm{w}}$ and $\mathrm{C}_{\mathrm{ij}}{ }^{\mathrm{v}}=\mathrm{c}_{\mathrm{kj}}{ }^{\mathrm{v}} \bullet \mathrm{S}_{\mathrm{kj}}{ }^{\mathrm{v}}$, so that once these bids and offers are submitted, the market maker calculates the accepted bids and offers by solving the following linear program:

$\operatorname{Max}_{\mathrm{a}, \mathrm{b}} \quad \Sigma_{\mathrm{i}} \Sigma_{\mathrm{j}} \Sigma_{\mathrm{r}} \mathrm{a}_{\mathrm{ij}}^{\mathrm{r}} \bullet \mathrm{P}_{\mathrm{ij}}{ }^{\mathrm{r}}-\Sigma_{\mathrm{k}} \Sigma_{\mathrm{j}} \Sigma_{\mathrm{g}} \mathrm{b}_{\mathrm{kj}}{ }^{\mathrm{g}} \bullet \mathrm{C}_{\mathrm{kj}}{ }^{\mathrm{g}}$

such that

$\mathrm{a}_{\mathrm{ijj}}{ }^{\mathrm{r}}, \mathrm{b}_{\mathrm{kj}}{ }^{\mathrm{g}} \in[0,1] \quad \forall \mathrm{i}, \mathrm{k}, \mathrm{j}, \mathrm{r}, \mathrm{g}$

$\Sigma_{\mathrm{i}} \Sigma_{\mathrm{r}} \mathrm{a}_{\mathrm{ij}}{ }^{\mathrm{r}} \bullet \mathrm{Q}_{\mathrm{ij}}{ }^{\mathrm{r}}-\Sigma_{\mathrm{k}} \Sigma_{\mathrm{g}} \mathrm{b}_{\mathrm{kj}}{ }^{\mathrm{g}} \bullet \mathrm{S}_{\mathrm{kj}}{ }^{\mathrm{g}}=0 \quad \forall \quad \mathrm{j}$

This is nothing more than finding the largest surplus such that supply equals demand for each commodity. The price paid by the "winners" is uniform for each $\mathrm{j}$ and is equal to:

$\mathrm{p}_{\mathrm{j}}=\left(\mathrm{p}_{\mathrm{j}}^{\mathrm{L}}+\mathrm{p}_{\mathrm{j}}^{\mathrm{H}}\right) / 2$

where

\footnotetext{
${ }^{8}$ If person $\mathrm{i}$ only submits $\mathrm{u}<\mathrm{m}$ bids, then $\mathrm{p}_{\mathrm{ij}}{ }^{\mathrm{z}}, \mathrm{Q}_{\mathrm{ij}}{ }^{\mathrm{z}}=0$ for $\mathrm{z}>\mathrm{u}$.
} 


$$
\begin{aligned}
& \mathrm{p}_{\mathrm{j}}{ }^{\mathrm{L}}= \begin{cases}\operatorname{Max}\left\{\mathrm{p}_{\mathrm{ij}}{ }^{\mathrm{r}}: \mathrm{a}_{\mathrm{ij}}{ }^{\mathrm{r}}=0 \text { and } \mathrm{p}_{\mathrm{ij}}{ }^{\mathrm{r}}>\mathrm{c}_{\mathrm{kj}}{ }^{\mathrm{g}} \text { for } \mathrm{b}_{\mathrm{kj}}{ }^{\mathrm{g}}>0\right\} & \text { (highest rejected bid) if it exists } \\
\mathrm{p}_{\mathrm{j}}{ }^{\mathrm{H}} & \text { otherwise }\end{cases} \\
& \mathrm{p}_{\mathrm{j}}{ }^{\mathrm{H}}= \begin{cases}\operatorname{Min}\left\{\mathrm{p}_{\mathrm{kj}}{ }^{\mathrm{g}}: \mathrm{b}_{\mathrm{kj}}{ }^{\mathrm{g}}=0 \text { and } \mathrm{p}_{\mathrm{ij}}{ }^{\mathrm{r}}>\mathrm{c}_{\mathrm{kj}}{ }^{\mathrm{g}} \text { for } \mathrm{a}_{\mathrm{ij}}{ }^{\mathrm{r}}>0\right\} & \text { (lowest rejected offer) if it exists } \\
\mathrm{p}_{\mathrm{j}}^{\mathrm{L}} & \text { otherwise }\end{cases}
\end{aligned}
$$

if neither $\mathrm{p}_{\mathrm{j}}^{\mathrm{L}}$ nor $\mathrm{p}_{\mathrm{j}}^{\mathrm{H}}$ exists as defined above, we use:

$\mathrm{p}_{\mathrm{j}}^{\mathrm{L}}=\operatorname{Min}\left\{\mathrm{p}_{\mathrm{ij}}^{\mathrm{r}}: \mathrm{a}_{\mathrm{ij}}^{\mathrm{r}}>0\right\}$

$\mathrm{p}_{\mathrm{j}}^{\mathrm{H}}=\operatorname{Max}\left\{\mathrm{c}_{\mathrm{kj}}^{\mathrm{g}}: \mathrm{b}_{\mathrm{kj}}^{\mathrm{r}}>0\right\}$

In single commodity markets with concave preferences and convex costs, UPDA has been found to be comparable in efficiency to the double auction (see Smith et al. (1982), Liu (1992) and Friedman (1993)). And, since UPDA produces a single uniform price for each commodity, it lacks the price volatility of the double auction. It would seem to be the natural way to organize a market for RECLAIM.

But there are features of the RECLAIM environment that could create difficulties for the performance of UPDA. We provide three examples where this might be true. We also provide supporting experimental evidence from testbedding to establish that indeed UPDA does not perform well in these situations.

\section{IV.A All or None Trades}

In RECLAIM, firms contemplating abatement equipment installation may want to either do it or not. It may be non-economic to take half measures. Thus, desired permit trades may be "all or none". UPDA can fail to make valuable trades when market orders can have "all or nothing" constraints. Consider the supply and demand condition depicted in Figure 1. In this situation, there are three buyers and three sellers. Buyer B1 has an 
inflexible demand for 5 units and a willingness to pay $\$ 70$ per unit, i.e. $\mathrm{V}_{1}(\mathrm{x})=350$ if $\mathrm{x}$ $=5$ and $V_{1}(x)=0$ otherwise where $V_{1}(x)$ is the maximum 1 is willing to pay for a total of $x$ units. Buyer B2 has demand such that $V_{2}(x)=40^{*} x$ for $x \leq 2$ and $V_{3}(x)=35^{*} x$ for $x$ $\leq 2$. Seller $\mathrm{S} 1$ has a cost of $C_{1}(x)=50 * x$ for $x \leq 3$, seller $S 2$ has a cost $C_{2}(x)=160$ if $x$ $=2$ and $C_{2}(x)=\infty$ if $x>2$ and $C_{3}(x)=90 * x$ for $x \leq 2$. It is easy to see that there is no uniform price equilibrium. It is impossible for UPDA to solve this problem unless some seller or buyer suffers a loss. There is no one-price equilibrium for the situation charted in Figure 1. But, there would be positive surplus if some trade were to occur at non-uniform prices. If seller 2 were to receive $\$ 80$ per unit for his two units, seller 1 were to receive $\$ 55$ for his three units and buyer 1 were to pay $\$ 65$ per unit for 5 units, then the budget would be balanced and surplus attained. ${ }^{9}$

This example also illustrates the concept of transaction risk. If Buyer 1 were to attempt to negotiate bilaterally with Seller 1 and Seller 2, then Buyer 2 would be happy to pay $\$ 55$ per unit to $\mathrm{S} 1$ and $\$ 80$ per unit to S2. B1 would end up paying $\$ 5$ less per unit then what he is willing to pay. In fact B1 is $\$ 25$ ahead of his willingness to pay. But, if the deal with $\mathrm{S} 1$ falls through or if $\mathrm{S} 1$ refuses to go below $\$ 65$, then B1 loses money, if B1 has made the deal with S2 already. In fact, if the deal falls through, the B1 loses \$20. If $\mathrm{B} 1$ pays $\$ 65$, he loses $\$ 5$. So in fact if $\mathrm{S} 1$ knows $\mathrm{B} 1$ is in this position, $\mathrm{S} 1$ can actually get B1 to pay up to $\$ 70$ per unit - she can hold B1 up. Knowing this B1 is going to be reluctant to deal separately with S1 and S2.

--- Figure 1 here ---

\section{B Returns to Scale}

One might argue assuming all or none preferences is unduly harsh even when facilities face increasing returns to scale in abatement technology. The values that traders have for the permits themselves are really induced via their opportunity cost. That is, participants have permits that they can use to either satisfy their own pollution demands or to sell

\footnotetext{
${ }^{9}$ All or none preferences are derivable from "avoidable cost" scenarios - a concept found in Van Boening and Wilcox (1996).
} 
them to others. If there are returns to scale in abatement technology, the derived values for permits might be simply superadditive. That is, for buyers, it might be that $d^{2} V(x) / d x^{2}>0$.

Consider for example the three markets (these are labeled A, B and C) depicted in Figure 2. Each is designed to capture the essential features of a reality that might cause a problem for UPDA. There are eight participants in these markets. In Markets A and C, each step in the graph represents a participant's marginal return function for the first three units. The marginal return for more than 3 units is zero. In Market A, there is no depth in the market since there are no extra marginal traders and there is a wide competitive price tunnel (\$13 - \$25). In Market C, there is one seller with no opportunity cost for 10 credits. ${ }^{10}$ Notice that in this market there is no uniform price equilibrium. As soon as the price goes above $\$ 35$ the marginal traders require 3 units or they will make negative profits. However, this will cause an excess demand and thus price must rise. At this point, either the outcome must result in losses or at least one bidder must forgo the pursuit of potentially profitable opportunities. In Market B, there are 10 units for sale. Each of the 4 demanders has superadditive values for up to 10 units. Thus, the most efficient outcome has one demander obtaining all the units from the sellers. There is a uniform price competitive equilibrium in this market at a price of $\$ 22$ (this is the average profit of the first rejected demander for 10 units). Values for participants in these markets can be found in Appendix A.

--- Figure 2 here ---

\section{C. Strong Complementarities}

In a multiple commodity situation, a subtler problem can arise. There may be conditions in which there are strong complements between the pollutants or between RTCs. The first occurs if a facility produces both NOx and SOx when it has production runs. The

${ }^{10}$ In Market $\mathrm{C}$ the only seller was the experimenter, who offered all 10 units at a zero price. 
second arises if a firm would need permits for 10 pounds in each of multiple years in order to substitute for abatement equipment. Thus, if the facility demands pollution credits, it may require them in complementary proportions. This would not necessarily create a situation in which competitive equilibrium does not exist, as in Figure 1, but it is known that strong complementarities cause problems for price discovery through the creation of bad income effects.

To establish this intuition we create an example in which bidders in Markets A and B must obtain fixed combinations of units of both $\mathrm{A}$ and $\mathrm{B}$ in order to obtain value. That is, $V_{i}\left(x_{A}, x_{B}\right)=0$ if $\left\{x_{A}, x_{B}\right\} \not \subset X_{i}$ where $X_{i}$ is a finite set of combinations that person $i$ values. The values we use for $V_{i}$ and $X_{i}$ can be found in Appendix $A$.

\section{IV.D. Experiments}

To determine if an iterative UPDA could provide for efficient outcomes in the difficult environments presented in IV.A. to IV.C., we conducted a series of experiments. Subjects were recruited from the undergraduate student population at the California Institute of Technology. All the subjects had experience in other market experiments. Each experimental session consisted of a single market instance. Each session ran on a computer network and lasted approximately 1.5 hours. For the returns to scale environment, each experimental session consisted of 3 commodities that were traded simultaneously. Subjects were assigned randomly to a set of redemption values, costs and endowments. Subjects were paid in cash at the end of the sessions.

Communication among subjects was not allowed during the experiment. While each subject knew her own valuations, costs, and endowments, she knew nothing about the valuations, costs, and endowments of the other subjects. Each subject knew the number of subjects in the experiment.

\footnotetext{
${ }^{11}$ In our design, there exists a competitive price equilibrium.
} 
Each experimental session consisted of a single market period consisting of a sequence of iterations. Each subject had approximately 10 minutes to enter orders and was limited to a fixed number of orders in each iteration. At the beginning of each iteration, the current market price and the number of units tentatively accepted for trading in each market were displayed on subject computer terminals.

Because there is no way for UPDA to create an allocation in market $\mathrm{C}$ without someone making a loss, we thought it unlikely any trade would occur in that market using UPDA. So rather than doing an experiment based solely on Figure 1, and then having a group of frustrated subjects on our hands, we used the all or nothing environment as a third market (Market C) beside the strong complements treatment. Two sessions were run. As expected, no trade occurred in either even though there were unexploited gains from trade.

Two sessions were conducted with the returns to scale environments. The volumes, prices and efficiencies for each market are provided in Figure 3. For each Market, the price, volume and efficiency for each iteration of the auction is provided in the Figures. Each session lasted 7 iterations before the markets closed. For Market A each session produced allocations that were at the $80 \%$ level of efficiency when the auction closed at iteration 7. Volume was significantly below the prediction of 15 units. Thus, UPDA did not do a good job of trading the marginal units. The same result occurs in Market B but volume of trade was slightly better. However in Market C efficiency was almost $100 \%$. Even though this Market had no competitive equilibrium, participants managed to keep prices below the danger level of $\$ 35 .^{12}$

---Figure 3 here ---

Two sessions were conducted with the strong complements environment. The results are shown in Figure 4. In session 1, the auction lasted 8 iterations before it closed. The

\footnotetext{
${ }^{13}$ Recall that a main difference in Market $\mathrm{C}$ relative to Markets A and B is that there are no sellers in Market C. The Experimenter offered all ten units at a zero price.
} 
prices, volumes and efficiencies for the complementary markets for each iteration are provided. Session 1 produced a mere 53\% efficiency. Session 2 lasted only 3 iterations before the auction closed with a closing efficiency of $66 \%$. There is a significant difference in prices between the sessions.

---Figure 4 here ---

\section{Conclusion}

The performance of UPDA in the five difficult situations can be easily summarized by the average efficiency measures.

\begin{tabular}{|l|l|}
\hline & Efficiency \\
\hline All or None & $0 \%$ \\
\hline Returns to Scale A & $80 \%$ \\
\hline Returns to Scale B & $80 \%$ \\
\hline Returns to Scale C & $100 \%$ \\
\hline Complements & $60 \%$ \\
\hline
\end{tabular}

It is clear that a standard call market design like UPDA cannot generate fully efficient allocations in all situations, especially in those that are created by non-convexities. Many of these problematic situations could easily be expected to occur for traders in the RECLAIM program. We needed to explore other designs.

\section{The Combined Value Call Market (CVCM)}

Because we expected the actual emission traders' preferences to be characterized by increasing returns, strong complementarities, and all or none constraints, we knew a simple UPDA call market was not going to be able to provide the desired performance. We needed a call market that would allow traders to bid in a way that would help solve their business financial problems. Our successful experience with combined value 
auctions (see Banks et.al. (1989)) naturally led us to consider a combined value market. ${ }^{13}$ We did this by (a) allowing bidders to submit contingent bids describing their preferences, (b) matching orders in the call by maximizing the "gains from trade" revealed by the bidders, (c) pricing the trades in a way that leaves bidders at least as well off as if they didn't trade and in a way that provides incentives to them to reveal their true willingness to trade, and (4) ensuring the auctioneer would neither extract excess surplus nor "trade ahead" of the matching process. ${ }^{14}$

In the rest of this section we describe our original design for the ACE combined value call market ${ }^{15}$. The general structure of our CVCM paralleled the iterative UPDA. In particular, at each iteration agents submit buy/sell orders; a tentative allocation is made that maximizes gains from trade (the sum of seller and buyer surplus), and tentative prices are computed for trades. Winning orders are automatically entered into the next iteration and can be replaced only if the revision would improve the gains from trade. Bidders can modify rejected bids in any manner and rebid if they win. If both surplus and volume do not increase by at least 5 percent after any iteration the market ends and transactions are made based on the allocation and prices of the last iteration. ${ }^{16}$

The designer must solve at least three problems. 1) What are allowable bids? 2) How do we determine which bids and offers to accept, and how do we accomplish this in a

\footnotetext{
${ }^{13}$ To our knowledge, at that time in 1993 , there had never previously been an operating combined value market. One exception could be our Cassini Resource Exchange (see, Ledyard et al. (1994)) but that was a barter system as opposed to a financial call market where quasi-linearity can be used in the selection of allocations.

${ }^{14}$ The mechanism does allow for transaction fees that are remuneration to the market designers and operators. The ACE market imposes a 3\% transaction free for each trade based on the value of the trade. This transaction fee is automatically taken into account in the bids and offers submitted in the market. We needed to imbed the transaction fee into the market due to the requirement that [this was self imposed because of clearance and settlement issues] individuals could not sell short or trade on margin. In order to guarantee RTC delivery and funds transfers from trades, participants are required to escrow their credits and funds prior to the market opening so that trades are ensured. Since transaction fees are part of the transfers they were incorporated into the bids so that no deficits are possible. This is just one of many practical issues we needed to address in the market design process

${ }^{15}$ As both the users of the market and we became more familiar with the way the CVCM performed, upgrades in the types of bids allowed and the pricing rule provided desired improvements. See, e.g., footnote 17 .

${ }^{16}$ In the actual market, there is a maximum of 5 and a minimum of 3 iterations per auction.
} 
reasonable amount of time? 3) How are prices computed and what do the agents pay? We take these up in order below.

\section{V.A. Orders}

Our combined value market allows for a variety of order types. A multi-market order for agent $\mathrm{i}$ is a vector $\left\langle\mathrm{b}_{\mathrm{i}}, \mathrm{q}_{\mathrm{i} 1}, \ldots ., \mathrm{q}_{\mathrm{in}}, \mathrm{F}_{\mathrm{i}}>\right.$ where:

- $\quad b_{i}>0$ means agent $i$ is willing to pay at most $b_{i}$ for the order,

- $\left[b_{\mathrm{i}}<0\right.$ means agent $\mathrm{i}$ is willing to accept at least $b_{\mathrm{i}}$ for the order.

- $\quad \mathrm{q}_{\mathrm{ij}}>0$ means agent $\mathrm{i}$ wants to purchase up to $\mathrm{q}_{\mathrm{ij}}$ units of $\mathrm{j}$ in the order,

- $\quad \mathrm{q}_{\mathrm{ij}}<0$ means agent $\mathrm{i}$ wants to sell up to $\mathrm{q}_{\mathrm{ij}}$ units of $\mathrm{j}$ in the order,

-[ $\mathrm{F}_{\mathrm{i}}$ is a scale factor $\left(0 \leq \mathrm{F}_{\mathrm{i}} \leq 1\right)$ which indicates that agent $\mathrm{i}$ is willing to accept one order of the form $\left\langle\mathrm{f}_{\mathrm{i}} \bullet \mathrm{b}_{\mathrm{i}}, \mathrm{f}_{\mathrm{i}} \bullet \mathrm{q}_{\mathrm{i} 1}, \ldots ., \mathrm{f}_{\mathrm{i}} \bullet \mathrm{q}_{\mathrm{in}},>\right.$ where $\mathrm{f}_{\mathrm{i}} \in\left[\mathrm{F}_{\mathrm{i}}, 1\right]$. For an "all or none" bid, $\mathrm{F}=1$.

Let's consider some examples. An order $<1000,(0,0,10), 0.6>$ for only one commodity indicates that the agent is willing to purchase any size order between 100 and 60 percent of the full order for asset 3. That is, he is willing to pay up to $\$ 1000$ for 10 units of asset 3 , or he is also willing to pay up to $\$ 600$ for 6 units of asset 3, or any convex combination of these orders. If $F_{i}>0$, we say that the agent's order is inflexible, and if $F_{i}=0$ then we say the agent is flexible. As we will see, inflexibility may come at a cost to the agent.

Orders may also be combined as packages. That is, an order may consist of a set of linked orders. For example, a package order can specify a willingness to pay up to $\$ 100$ for 10 units of asset 2, 20 units of asset 3 and 30 units of asset 4. That would look like $<100,(0,10,20,30), 0\rangle$. A packaged order may also consist of a swap, which consists of 
buying units of some assets and selling units of other assets. For example, a swap order can specify a willingness to pay up to $\$ 10$ to supply 10 units of asset 4 if and only if 10 units of asset 2 are received. This would be $\langle-10,(0,-2,0,10), 0\rangle$.

Orders are also allowed to be connected by logical XORs (exclusive OR's). An XOR is a logical element that binds one or more orders together. For example, an agent is able to submit an order that states a willingness to transact one and only one of "purchase 10 units of asset 3 for up to $\$ 10$ " or "purchase 20 units of asset 4 for up to $\$ 20$ ". This is equivalent to saying that out of a set of orders, at most one of the orders should be accepted.

\section{V.B. Matching}

We will now use i to denote orders as opposed to agent identification to reduce the notational burdens. The allocation at each iteration is determined by solving the integer program:

$$
\mathrm{V}^{*}=\underset{\mathrm{f}}{\operatorname{Maximize}} \Sigma_{\mathrm{i}} \mathrm{b}_{\mathrm{i}} \bullet \mathrm{f}_{\mathrm{i}}
$$

subject to

$\mathrm{d}_{\mathrm{i}} \in\{0,1\} ; \mathrm{d}_{\mathrm{i}} \mathrm{F}_{\mathrm{i}} \leq \mathrm{f}_{\mathrm{i}} \leq \mathrm{d}_{\mathrm{i}} \quad$ feasibility

$\Sigma_{\mathrm{i}} \mathrm{f}_{\mathrm{i}} \bullet \mathrm{q}_{\mathrm{ij}} \leq 0 \quad \forall \mathrm{j}$

no excess demand

$\Sigma_{\mathrm{k}_{\in} \mathrm{Mi}} \mathrm{d}_{\mathrm{k}} \leq 1 \quad \forall \mathrm{M}_{\mathrm{i}}$

XOR constraints

$V^{*}>0$ positive gains from exchange

Thus, if $d_{i}=0$ then order $i$ is not filled, while if $d_{i} \neq 0$ then order $i$ is filled up to the scaled amount $\mathrm{f}_{\mathrm{i}}$. Due to the discrete nature of the packaged bids, there can be cases in which there are gains from exchange, but demand is less than supply $\Sigma_{\mathrm{i}} \mathrm{d}_{\mathrm{i}} \bullet \mathrm{q}_{\mathrm{ij}}<0$ for some $\mathrm{j}$. In this case, the exchange is made and the untransacted RTCs are retired unused. (There is free disposal.) The set $\mathrm{M}_{\mathrm{i}}$ is the set of orders that are "ORed" with order $\mathrm{i}$. 
Conceptually, the allocation problem takes submitted bids and maximizes revealed surplus given demand and supply constraints and contingent constraints. This is a mixedinteger linear program (MILP) and there are many techniques to solve this type of problem (see Skiena (1997)). With 128 different RTCs and a large number of bids, this may not be computable in a reasonable length of time. For our initial market we broke the RTCs into four smaller markets: NOx zone 1, NOx zone 2, SOx zone 1, SOx zone 2; each one of these submarkets has 32 RTCs. In addition, there were restrictions placed on bids that retained the packaging and contingent capabilities but also reduced the computational burden ${ }^{17}$.

\section{V.C. Pricing}

After the allocation is computed in (5)-(9), we know which bids will be matched and completed. But we also need to compute what each matched bid will pay or receive. That is we need to compute the transaction prices. As we stated earlier, the principles we used in designing the pricing rule were: (a) payments equal receipts among the bidders, (b) no one pays more (receives less) than they bid (offer), (c) there are incentives to reveal one's true willingness to pay, and (d) everyone pays the same price per unit unless there are significant reasons for deviating. As we will see below, deviations from these principles will occur only in cases with important inflexibilities.

After the allocation problem is solved there will be three categories of orders:

(i) $[$ those orders that were accepted by the allocation;

(ii) $\square$ those orders that were rejected by the allocation; and

\footnotetext{
${ }^{17}$ As the traders and we developed familiarity with the performance of the combined value call market in the real world, new features were requested and added. New types of bids were allowed. For example, a "zone free" bid was implemented which left it to the computer to decide which permits one could buy and then to compute the least cost trade to fulfill my goals. A similar setup was introduced to allow for "cycle free" trading. Each new type of trade required revisions to the optimization program and to the pricing rules (primarily to eliminate arbitrage opportunities). Another paper is being prepared which will provide more of these details.
} 
(iii)] those orders that were partially accepted and rejected (that is, $0<\mathrm{f}<1$, where $\mathrm{f}$ is the allocated fraction in the order). We will treat the accepted part as an accepted order and the rejected part as a rejected order.

In addition, some of these orders will have been part of an XOR order.

A little economics will now take us a long way. Think about the entire collection of submitted orders as a quasi-linear economy and ask what a market equilibrium (a competitive equilibrium) would look like. It is easy to show that, if a competitive equilibrium allocation and price vector $p$ exist then the allocation would solve the allocation problem in (5) - (9) and the prices $\mathrm{p}$ (one price for each item) would solve

$b_{i}-p \bullet q_{i} \geq 0 \quad$ for all accepted orders

$b_{i}-p \bullet q_{i} \leq 0 \quad$ for all rejected bids

$b_{i k}-p \bullet q_{i k} \geq b_{i k^{*}-p} \bullet q_{i k^{*}} \quad$ if ik is accepted and ik* is ORed with ik

$p \bullet \sum_{i_{\in} A} q_{i}=0 \quad$ Walras Law

(Note that $b_{i}-p \bullet q_{i}=0$ for any bid which is only partially accepted.)

If such a market equilibrium price exists, it would satisfy our principles and would be the natural price to set. Unfortunately, neither the uniqueness nor the existence of such a price vector $p$ is guaranteed.

If the market equilibrium prices exist but are not unique, there are many ways to pick one. We use a "split-the-difference" rule. Specifically, we

(i)] Find the competitive equilibrium price that maximizes the net surplus to the buyers (a vector of "low" prices);

(ii) $[$ Find the competitive equilibrium price that maximizes the net surplus to the sellers (a vector "high" prices); and

(iii) $]$ For each commodity, we take the midpoint of (i) and (ii). 
To see how this works look at figure 5. If all orders are fully flexible (that is, $\mathrm{F}=0$ ) and there are no XOR constraints, then any price from $\$ 2$ to $\$ 3$ would be a competitive equilibrium price. Our "split-the-difference" rule would select a price of \$2.50/unit.

--- Figure 5 here---

Non-existence is a deeper problem requiring somewhat more finesse. ${ }^{18}$ To see what the problem is, look again at Figure 5. Suppose now that Buyer (B1) has an inflexible order and is willing to pay up to $\$ 9$ for 3 units and no fewer. Further suppose Seller (S1) has an inflexible order and is willing to sell 2 units for at least \$4. Lastly, suppose Seller (S2) is willing to sell 1 unit for at least $\$ 4$. Surplus is maximized, given the flexibility constraints, if and only if all orders are filled. This is the only feasible allocation yielding positive surplus. There is, however, no competitive equilibrium. To see this, observe that at any price above $\$ 3$ per unit, B1 is unwilling to buy units, and at any price below $\$ 4$ per unit, S2 is unwilling to sell any units.

To price out the allocation when a market equilibrium price does not exist, we construct a "pseudo-competitive equilibrium price." First, we ignore rejected orders ${ }^{19}$ and consider only the accepted orders, i.e., orders i such that $\mathrm{d}_{i}{ }^{*} \neq 0$. We then calculate a fully flexible allocation by maximizing the surplus, subject to no excess demand, with $\mathrm{d}_{\mathrm{i}}{ }^{*} \in[0,1]$. This is the allocation that would occur if all orders were fully flexible. Next, we find prices for this allocation exactly as we did before; splitting the difference if the competitive equilibrium price is not unique. (In this case it is easy to show an equilibrium price will exist.) In Figure 5, this means that the price is $\$ 2.50$; the price that would obtain if all orders were fully flexible $(\mathrm{F}=0)$.

\footnotetext{
${ }^{18}$ When Cantor-Fitzgerald created a version of a combined value market in response to ACE (see Marron and Bartels), they recognized this problem. But they solved it by constraining the original match to only consider a set of bids for which a competitive price would exist. This of course reduces the possible trades that will be matched and in some cases, such as those in Figures 5-7 below, will lead to no trade - even though there are obvious gains from exchange. We did not want to lose those trades.

${ }^{19}$ This means that at the pseudo price it is possible that $\mathrm{b}_{\mathrm{i}}-\mathrm{p} \bullet \mathrm{q}_{\mathrm{i}}>0$ for rejected orders.
} 
But we are still not quite finished. If we were to charge and pay every bid according to the price of $\$ 2.50$, Seller 2 would be receiving less than the minimum her bid indicated she was willing to accept per unit (\$4.00). Further, even though Buyer 1 created the nonexistence problem by requiring his bid be all-or-none, he would receive a surplus of $\$ 0.50$ on the extra unit sold that way. To provide the right incentives, to minimize all-ornone bids, and to not over-charge or under-pay, we charge or pay each part of an originally accepted bid that was rejected in the fully flexible allocation exactly what they bid. So in Figure 5, Seller 2 will receive $\$ 4$ for her unit and Buyer 1 will pay $\$ 3$ for the last unit.

But if we do this we still have a problem. If Seller 1 receives $\$ 2.50 /$ unit sold and buyer 1 pays $\$ 2.50 /$ unit for the first two units bought we will have to pay out more than we receive. In fact, the area indicated as negative surplus in Figure 6 is exactly the amount we will be short. Let $\mathrm{V}^{\mathrm{f}}$ denote the surplus from the fully flexible allocation, $\mathrm{V}^{*}$ denote the surplus from the original matching procedure, and let $d V=V^{f}-V^{*}$, the added surplus from flexibility. $\mathrm{dV}$ is exactly the negative surplus in Figure 6 . We need to collect this amount from those bids accepted in the fully flexible allocation. There are many ways to carry out this accommodation of the inflexible bidders. In the pollution market design, we chose to split price prices and charge buyers a different (and higher) price than we paid sellers. In particular, we took the price from the flexible allocation and added and subtracted an amount $\Delta \mathrm{p}$. Buyers will pay $\mathrm{p}+\Delta \mathrm{p}$ and sellers will receive $\mathrm{p}-\Delta \mathrm{p} . \Delta \mathrm{p}$ is chosen so that $(2 \Delta \mathrm{p})^{*} \mathrm{q}=\mathrm{dV}$, where $\mathrm{q}$ is the volume traded in the fully flexible allocation. For the example in Figure 5 and $6, \Delta p=\$ 0.25$. So, in that example, Seller 1 receives $\$ 2.25 /$ unit sold for a gain over her stated willingness to accept of $\$ 0.50$. Seller 2 receives $\$ 4.00 /$ unit for a gain of $\$ 0.00$ and Buyer 1 pays $\$ 2.75 /$ unit for two units and $\$ 3.00$ for one unit for a gain of $\$ 0.50$. The total surplus from the trade is $\$ 1.00$ and that is split between the three traders.

You may have noticed that if Buyer 2 were really two people - say, Buyer 2' and Buyer $2 "$, where Buyer 2' wanted one unit for $\$ 3.50$ and Buyer 2" wanted one unit for $\$ 2.40$, we could not implement the pricing scheme as it is so far. The fully flexible price would be 
$\$ 2.20$ and when we went to split prices we could not pick a $\Delta$ p that would leave Buyer 2" paying less than or equal to what the willingness to pay is. In this case we stop at a $\Delta p$ that puts him at zero surplus (here that is $\$ 0.20$ ). Remove him from the computation and continue to split prices for the others until we just balance payments and receipts.

A somewhat more complicated example illustrating this is given in Figure 7. In this Figure, B1 is willing to pay $\$ 9$ for 1 unit and B2 is willing to pay $\$ 9$ for 3 units. $S 1$ is willing to sell 2 units for $\$ 4$ and S2 is willing to sell 2 units for $\$ 8.20$. All orders are inflexible. In this case the full allocation gives a surplus of $\$ 5.80$.

---Figure 7 here --

At the fully flexible allocation, $\mathrm{q}=2$ and the price is $\$ 2.50$. Since B2 and S2 are extramarginal, $\mathrm{S} 2$ receives his ask price of $\$ 4.10$ for each of his 2 units and B2 receives his bid price of $\$ 3$ for each of his 2 extra-marginal units. This leaves a deficit of $\$ 2.20$ that must be made up by the difference between the price B1 pays for his unit, the price B2 pays for his infra-marginal unit, and the price S1 receives for his units. Splitting prices leads us to hit the willingness to pay of Buyer 2 and the willingness to accept of Seller 1. So we end up with Seller 1 receiving exactly what she bid, Buyer 2 paying exactly what he bid. We then continue to raise the buy price until receipts balance against payments. This leaves Buyer 1 paying \$3.20.

The above may seem a convoluted way to match and price combined value trades. It is made particularly difficult when one allows all-or-none trades. But the proof is in the performance. We tested that in the economics lab and now turn to those results.

\section{Experimental Results}

In this section we describe the results of experiments with this new market design-the combined value call market (CVCM). As with the UPDA experiments, 
subjects were recruited from the undergraduate student population at the California Institute of Technology. All the subjects had experience in other market experiments and participated in a 90-minute train session the day prior to the experiments to become familiar with the auction rules and software (they were paid a flat $\$ 20$ fee for the training session). Each experimental session consisted of a single market instance. Each session was run on a computer network and lasted approximately 1.5 hours. Experimental sessions consisted of 3 commodities that were traded simultaneously. Subjects were assigned randomly to a set of redemption values, costs and endowments. All subjects were paid in cash at the end of the experimental sessions.

\section{VI.A. Returns-to-scale}

The results for the returns-to-scale environments are given in Figure 8. The superadditive values are the same as those found in Appendix A. The same as were used with UPDA. The Figure shows the prices, volumes and efficiency for each market. Coincidentally, the combined value markets lasted 7 iterations, exactly the same as with UPDA. However, unlike UPDA, the CVCM produced 100\% allocations in all sessions and markets. CVCM starts off at relatively high efficiencies and reaches over $90 \%$ efficiency by iteration 4 . Thus, we find:

CVCM outperforms UPDA in the returns-to-scale environments. CVCM produces $100 \%$ efficient allocations.

--- Figure 8 here ---

\section{VI.B. Strong Complements}

Two sessions, with the same strong complements environment we used to test UPDA, were run to test the CVCM. The results from these sessions can be found in Figure 9. Session 1 lasted 7 iterations before the market closed and session 2 lasted 5 iterations. 
The results were very similar with outcomes of $90 \%$ and $100 \%$ efficiencies. Again we find:

CVCM outperforms UPDA in the environments with complements CVCM produces near $100 \%$ efficient allocations.

---Figure 9 here ---

\section{IV.C. All or None}

In Figure 1 we illustrated an environment with "all or none" payoffs in which UPDA simply could not perform. To see how this type of market is handled by the CVCM, we conducted two sessions with the parameters defined in Figure 10. The main difference between this environment and the one charted in Figure 1 is that there is more surplus in the market. Also, costs and values are scaled down. The results of these experiments can be found in Figure 11. If any trade takes place it must be at 100\% efficiency. In UPDA, no trade ever occurred. In CVCM, during the first few iterations, no trade occurs also. But unlike UPDA, CVCM finally facilitated trades even in this very difficult situation. The prices for the buyer and sellers are charted in the figure for both sessions. The mechanism found a set of prices that split the surplus between seller 1 and the buyer with seller 2 receiving his offer price.

---Figure 10 here---

---Figure 11 here---

\section{Conclusions}

RECLAIM was created as an emissions trading program. In an attempt to retain regulatory control over the temporal and spatial distribution of pollutants, the program established 128 different market commodities. A complex collection of psuedo-property 
rights exists that makes identifying and completing trades very difficult. The derived value of the permits, what facilities are willing to pay or accept to trade them, has a structure that makes it difficult for even single commodity markets to work effectively. All-or-none trades are desirable, and returns to scale abound. Strong complementarities between commodities create further difficulties. Adding to these problems for traditional markets, the program is thin with a small number of participants and there is no history of market trades to provide information for price discovery.

To design a market for RECLAIM, we first studied the performance of a "traditional" call market in these situations. A Uniform Price Double Auction was test-bedded. It did not perform well . It never did match buyers and sellers in all-or-none situations. It produced only 55-66\% of the potential gains from exchange in situations with strong complements. UPDA simply cannot handle non-convexities.

We designed and created a combined value call market we believed would be able to handle non-convexities. The market was designed to allow buyers and sellers to tailor their orders so entire portfolios of credits can be traded. The main incentive feature of the market is a pricing rule that calculates prices from marginal traders so inframarginal traders have an incentive to reveal values and costs. The combined value nature of the allocation process allows the inframarginal portfolio traders to fully reveal without the danger of financial exposure.

We testbedded the Combined Value Market in the same environments that we tested the Uniform Price Auction. It significantly out-performed UPDA. In fact it matched buyers and sellers for $100 \%$ or nearly $100 \%$ of the potential gains from trade in all situations in which is was used.

The experiments conducted in this paper show that this market design allocates units at near $100 \%$ efficiency, which a Uniform Price Auction run separately for each permit type can not come close to producing. 


\section{References}

Atkinson and Tietenberg (1991), "Market Failure in Incentive-Based Regulation: the Case of Emissions Trading" Journal of Environmental Economics and Management 21:17-31.

Banks, Jeffrey, S., John O. Ledyard, and David P. Porter (1989), "Allocating uncertain and unresponsive resources: an experimental approach," RAND Journal of Economics, Vol. 20, No. 1, Spring.

Burtaw, Dallas (1994), "The $\mathrm{SO}_{2}$ emissions trading program: cost savings without allowance trades," Contemporary Economic Policy, 14, 79-94.

Campbell, J., LaMaster, S., Smith, V., and Van Boening, M. "Off-floor Trading, Disintegration and the Bid-Ask Spread in Experimental Markets." The Journal of Business, Vol. 64 (1991), pp. 495-522.

Carlson, Dale, Charles Forman, John Ledyard, Nancy Olmstead, Charles Plott, David Porter, and Anne Sholtz (1993), An Analysis and Recommendation for the Terms of the RECLAIM Trading Credit, Pacific Stock Exchange Technical Report, April 27, 1993.

Cason, Timothy (1995), An experimental investigation of the seller's incentives in EPA's emission trading auction," American Economic Review, 85, 905-22.

Cason Timothy and Charles Plott (1996), EPA's new emissions trading mechanism: a laboratory evaluation," Journal of Environmental Economics and Management, 30, 13360 .

Davis, Douglas D. and Charles A. Holt (1993),Experimental Economics, Princeton University Press, Princeton, New Jersey.

Friedman, Daniel (1993), "How trading institutions affect financial market performance: some laboratory evidence," Economic Inquiry.

Hahn, Robert and Gordon Hester (1989), "Where did all the markets go?" Yale Journal on Regulation, 6, 109-53.

Ishikida, T., J. Ledyard, M. Olson, and D. Porter (1999), "A Two-Sided Packaging Mechanism for Allocating Pollution Emission Credits: Results from Southern California's RECLAIM Market," mimeo, California Institute of Technology.

Joskow, Paul, Richard Schmalensee, and Elizabeth Bailey (1999), "The Market for Sulfur Dioxide Emissions," American Economic Review. 
Ledyard, John (1993), "The design of coordination mechanisms and organizational computing," Journal of Organizational Computing, 1.

Liu, Yu-Jane (1992), "Auction mechanisms and information structure: an experimental study of information aggregation in security markets," Mimeo. National Chung Cheng University, Taiwan.

Marron, Donald B., and Carlton W. Bartels, "The Use of Computer-Assisted Auctions for Allocating Tradable Pollution Permits," in Market-Based Control: A Paradigm for Distributed Resource Allocation, S. Clearwater, Ed., World Scientific Pub. Co., New York

McCabe, Kevin A., Stephen J. Rassenti, and Vernon L. Smith (1993), "Designing a uniform-price double-auction: an experimental evaluation," in The Double Auction Market, Eds. D. Friedman and J. Rust, SFI Studies in the Sciences of Complexity, Proc. Vol. XIV, Addison--Wesley, 1993.

Milgrom, Paul (1997), "Putting auction theory to work: the simultaneous ascending auction, mimeo, Stanford University.

Montgomery, David (1972), "Markets in licenses and efficient pollution control programs," Journal of Economic Theory, 395-418.

Plott, C. (1994), “'Market architectures, institutional landscapes, and testbed experiments", Economic Theory, 4, 3--10.

Skiena, Steven (1997), The Algorithm Design Manual, Springer-Verlag, New York.

Smith, Vernon L., Arlington W. Williams, W. Kenneth Bratton, and Michael G. Vannoni (1982), "Competitive market institutions: double auctions versus sealed bid--offer auctions," American Economic Review, 72, 58--77.

Van Boening, Mark (1991), Call Versus Continuous Auctions: An Experimental Study of Market Organization. Dissertation, University of Arizona.

Van Boening, Mark and Matt Wilcox (1996) "Avoidable cost: ride a double auction roller coaster," American Economic Review, vol. 86: pp. 461-477 
Appendix A

Environment Values

Superadditive Values*

\begin{tabular}{|l|l|l|l|l|l|l|l|l|}
\hline Subject & 1 & 2 & 3 & 4 & 5 & 6 & 7 & 8 \\
\hline $\begin{array}{l}\text { Endowment } \\
\text { Market A }\end{array}$ & 0 & 0 & 0 & 0 & 0 & 5 & 5 & 5 \\
\hline Value Unit1 & 20 & 20 & 20 & 20 & 20 & 15 & 15 & 15 \\
\hline Unit 2 & 35 & 30 & 30 & 25 & 20 & 12 & 12 & 12 \\
\hline Unit 3 & 45 & 40 & 35 & 30 & 25 & 11 & 11 & 11 \\
\hline Unit 4 & 0 & 0 & 0 & 0 & 0 & 0 & 0 & 0 \\
\hline \hline $\begin{array}{l}\text { Endowment } \\
\text { Market B }\end{array}$ & 0 & 0 & 0 & 0 & 3 & 3 & 2 & 2 \\
\hline Value Unit 1 & 27 & 13 & 7 & 5 & 25 & 25 & 25 & 27 \\
\hline Unit 2 & 28 & 15 & 10 & 9 & 21 & 19 & 13 & 15 \\
\hline Unit 3 & 29 & 17 & 13 & 13 & 18 & 17 & 10 & 10 \\
\hline Unit 4 & 30 & 19 & 16 & 17 & 7 & 7 & 7 & 7 \\
\hline Unit 5 & 31 & 21 & 19 & 21 & 5 & 5 & 5 & 5 \\
\hline Unit 6 & 32 & 23 & 21 & 25 & 0 & 0 & 0 & 0 \\
\hline Unit 7 & 33 & 25 & 24 & 29 & 0 & 0 & 0 & 0 \\
\hline Unit 8 & 34 & 27 & 27 & 33 & 0 & 0 & 0 & 0 \\
\hline Unit 9 & 35 & 29 & 30 & 37 & 0 & 0 & 0 & 0 \\
\hline Unit 10 & 36 & 31 & 33 & 40 & 0 & 0 & 0 & 0 \\
\hline \hline $\begin{array}{l}\text { Endowment } \\
\text { Market C }\end{array}$ & 0 & 0 & 0 & 0 & 0 & 0 & 0 & 0 \\
\hline Value Unit 1 & 50 & 50 & 50 & 30 & 30 & 35 & 35 & 35 \\
\hline Unit 2 & 58 & 58 & 58 & 55 & 55 & 60 & 60 & 606 \\
\hline Unit 3 & 60 & 60 & 60 & 60 & 60 & 65 & 65 & 65 \\
\hline
\end{tabular}

$*$ Values are in experimental currency -- francs; 1 franc $=\$ .50$ 
Strong Complements Values*

\begin{tabular}{|c|c|c|c|c|c|c|c|}
\hline Bidder ID & $\begin{array}{c}\text { Amount } \\
\text { of } \mathrm{A}\end{array}$ & $\begin{array}{c}\text { Amount } \\
\text { of } \mathrm{B}\end{array}$ & Value & Bidder ID & $\begin{array}{c}\text { Amount } \\
\text { of A }\end{array}$ & $\begin{array}{c}\text { Amount } \\
\text { of B }\end{array}$ & Value \\
\hline 1 & 4 & 3 & 100 & 2 & 3 & 6 & 125 \\
\hline 1 & 7 & 3 & 175 & 2 & 3 & 10 & 150 \\
\hline 1 & 12 & 3 & 250 & 2 & 3 & 14 & 175 \\
\hline 1 & 4 & 9 & 150 & 2 & 9 & 6 & 175 \\
\hline 1 & 7 & 9 & 225 & 2 & 9 & 10 & 190 \\
\hline 1 & 12 & 9 & 325 & 2 & 9 & 14 & 200 \\
\hline 1 & 4 & 13 & 175 & 2 & 15 & 6 & 200 \\
\hline 1 & 7 & 13 & 250 & 2 & 15 & 10 & 225 \\
\hline 1 & 12 & 13 & 335 & 2 & 15 & 14 & 250 \\
\hline 3 & 3 & 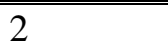 & 75 & 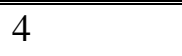 & 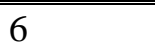 & 8 & 100 \\
\hline 3 & 3 & 4 & 100 & 4 & 6 & 10 & 150 \\
\hline 3 & 3 & 9 & 125 & 4 & 6 & 12 & 200 \\
\hline 3 & 5 & 2 & 100 & 4 & 8 & 8 & 150 \\
\hline 3 & 5 & 4 & 200 & 4 & 8 & 10 & 200 \\
\hline 3 & 5 & 9 & 225 & 4 & 8 & 12 & 275 \\
\hline 3 & 12 & 2 & 175 & 4 & 12 & 8 & 175 \\
\hline 3 & 12 & 4 & 250 & 4 & 12 & 10 & 250 \\
\hline 3 & 12 & 9 & 275 & 4 & 12 & 12 & 300 \\
\hline$\overline{5}$ & 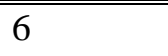 & 7 & 175 & 6 & 7 & 7 & 75 \\
\hline 5 & 6 & 10 & 225 & 6 & 7 & 9 & 150 \\
\hline 5 & 6 & 13 & 250 & 6 & 7 & 11 & 175 \\
\hline 5 & 9 & 7 & 225 & 6 & 9 & 7 & 125 \\
\hline 5 & 9 & 10 & 275 & 6 & 9 & 9 & 175 \\
\hline 5 & 9 & 13 & 300 & 6 & 9 & 11 & 2000 \\
\hline 5 & 12 & 7 & 250 & 6 & 11 & 7 & 150 \\
\hline 5 & 12 & 10 & 300 & 6 & 11 & 9 & 200 \\
\hline 5 & 12 & 13 & 325 & 6 & 11 & 11 & 225 \\
\hline
\end{tabular}

$*$ Values are in experimental currency -- francs; 1 franc $=\$ .10$ 


\section{Appendix B}

\section{Instructions for TSC}

You are about to participate in an economic experiment in which you will earn money based on the decisions you make. All earnings you make in the experiment are yours to keep. Here are some important features of our experiment:

-[ All accounting (values, prices and costs) will be stated in francs. Each franc you earn can be converted into US currency at the rate specified on your Opportunities Sheet (see below).

- We will be conducting a Market in which you can buy and/or sell the items found on your Opportunities Sheet.

-[ The Market will consist of Rounds in which you will make decisions. You only earn francs when the Market closes, not for each Round of the Market.

- $\square$ When the Market closes you will fill out your Accounting Sheet and a monitor will verify your earnings and accounting.

\section{The Opportunities Sheet}

Your Opportunities Sheet is private information; you should not reveal it to anyone. This sheet lists items (A, B, C) that you can buy or sell. Below you will find a sample sheet for participant 10 who has a franc conversion rate of ___ francs to a dollar. In addition, this participant must pay __ francs to use the sheet. This participant has an inventory of units of item A, _ units of B, and _ units of C. Each participant is free to sell up

to, but not beyond, the number of units they have in their inventory. Under each item there is a value listed in francs for the number of units; you finally hold when the market closes. The last column in the table lists the additional value of getting the particular 
package combination of the items. For example, if the participant were to get 1 unit of B she would receive __ francs; if she were to get two units of B she would get an additional _ _ francs or a total of __ francs. If the participant obtained __ units of A and __ units of $\mathrm{C}$ she would get ___ francs in value.

Earnings for a period are equal to the sum of the values obtained plus revenue from units sold in the market minus the cost of the units bought in the market. For example, if at the end of the period the participant sold 3 units of $\mathrm{C}$ at __ francs each; and bought 2 units of B at a price of __ her earnings for the period would be:

\section{OPPORTUNITIES SHEET}

\section{Period}

Participant ___ Conversion Rate ___ francs $=\ldots$ Dollars

Cost

\begin{tabular}{|c|c|c|c|c|c|c|}
\hline \multicolumn{2}{|c|}{ A Market } & \multicolumn{2}{|c|}{ B Market } & \multicolumn{2}{|c|}{ C Market } & \multirow{2}{*}{$\begin{array}{r}\text { Package } \\
\text { Value } \\
\end{array}$} \\
\hline Units & Value & Units & Value & Units & Value & \\
\hline & & & & & & \\
\hline & & & & & & \\
\hline & & & & & & \\
\hline & & & & & & \\
\hline & & & & & & \\
\hline & & & & & & \\
\hline & & & & & & \\
\hline & & & & & & \\
\hline & & & & & & \\
\hline & & & & & & \\
\hline & & & & & & \\
\hline & & & & & & \\
\hline & & & & & & \\
\hline & & & & & & \\
\hline & & & & & & \\
\hline
\end{tabular}

\section{INITIAL INVENTORY}
$\mathbf{A}=$
$\mathbf{B}=$
$\mathrm{C}=$ 


\section{Accounting Sheet}

When the market closes you must fill out an accounting statement for the period.

Attached to these instructions you will find an accounting sheet. Just fill in the lines of the form and make the proper additions and subtractions.

\section{How the Market Trading Systems Works}

\section{Submitting an Order}

The market is divided into rounds in which you can submit orders to the market. An order is a listing of the items $\mathrm{A}, \mathrm{B}$ and $\mathrm{C}$ along with a franc amount. A minus entry means that you want to sell the specified number of units and a positive entry means you want to buy the specified number of units. In the franc position a negative amount (let us call it your sell offer) implies you want to receive the specified amount or more; a positive sign (let us call this your buy offer) implies you are willing to pay that amount or less. Below you will find an example. There are four upper boxes in the ORDER FORM which lists each of the items $\mathrm{A}, \mathrm{B}$ and $\mathrm{C}$ along with a box for francs. Next to each item in parentheses, is the amount of units you are allowed to sell in the market and the amount of francs you have in your credit line. In the example order form below, the order is to sell 10 units of $\mathrm{A}$ and buy 2 units of $\mathrm{B}$ and 4 units of $\mathrm{C}$. The entire package is offered with a buy offer of 6 francs or less.

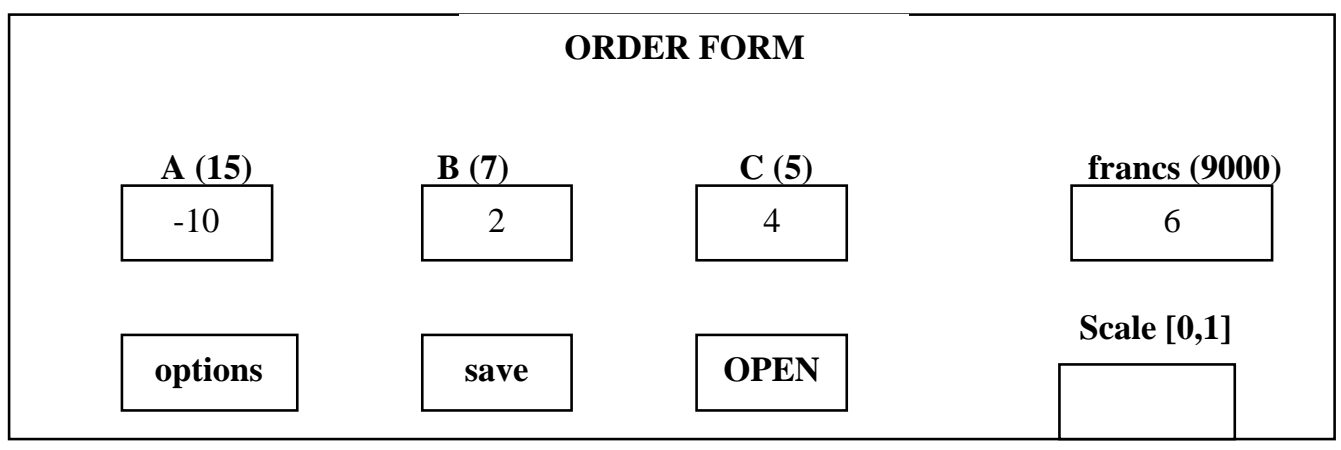


There are several features of the above order that are important:

- The order is for a package of items. It is an all or nothing order in that the entire amounts

$-10 \mathrm{~A}, 4 \mathrm{~B}$ and $2 \mathrm{C}$ must be filled if the order is to be a valid transaction.

-[ The franc amount is a total package price offered, not a per unit price for a specific item.

-[ A buy offer is an upper bound on what you are willing to pay. A sell offer is a lower bound on the amount of francs you are willing to receive for the order.

\section{Tailoring Your Order}

Your order can be customized in three ways that may assist you in obtaining a desired transaction.

Scaleable Orders Recall that the order placed in the above example was all or nothing. You can request that the order be less restrictive. You do this by submitting a scale number between 0 and 1 that you would be willing to scale your order to get it accepted. The best way to explain this feature is by an example. In the order form below a scale of .5 is submitted with the order. This means that you want to sell at least 5 units of A and buy at least 1 unit of $\mathrm{B}$ and 2 units of $\mathrm{C}$ for a package price of 3 francs. That is, all units are scaled by one-half. The scale also means that you are willing to scale up your order from this minimum in all dimensions up to the full order.

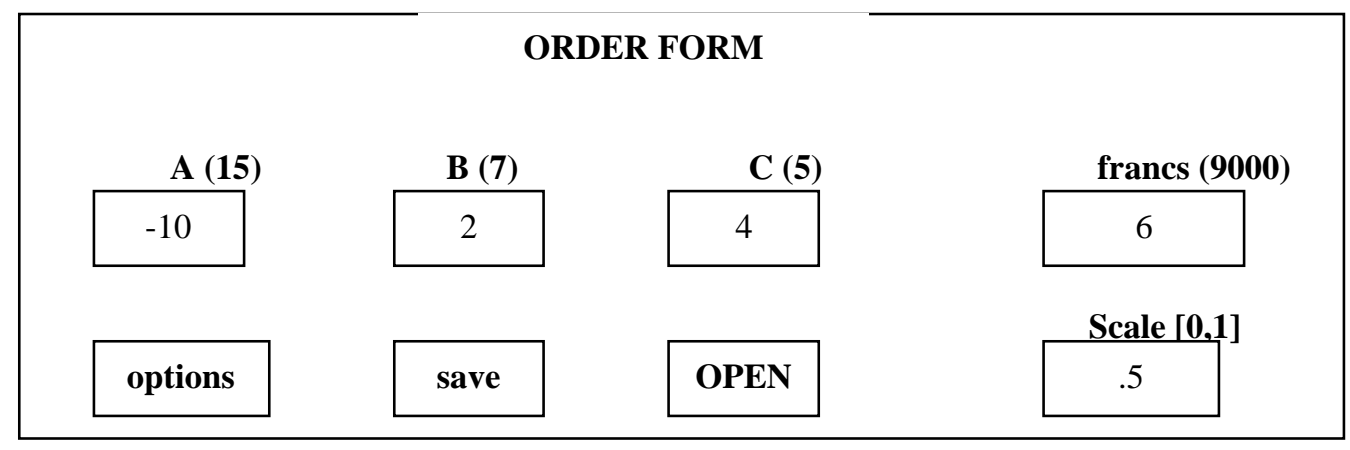


Contingent Orders If you submit more than one order you can tie your orders together. When two orders are tied together they become linked so that if one of them is accepted the other will not be accepted. In the example below, the bidder has two orders (Ids 4 and 5) that he has already constructed and wants his current order of $-10 \mathrm{~A}, 2 \mathrm{~B}, 4 \mathrm{C}$ at a buy offer of 6 to be contingent with orders 4 and 5 . He does this by tying them together with the same Con Id. This means that at most one of the orders with the same Con Id will be filled.

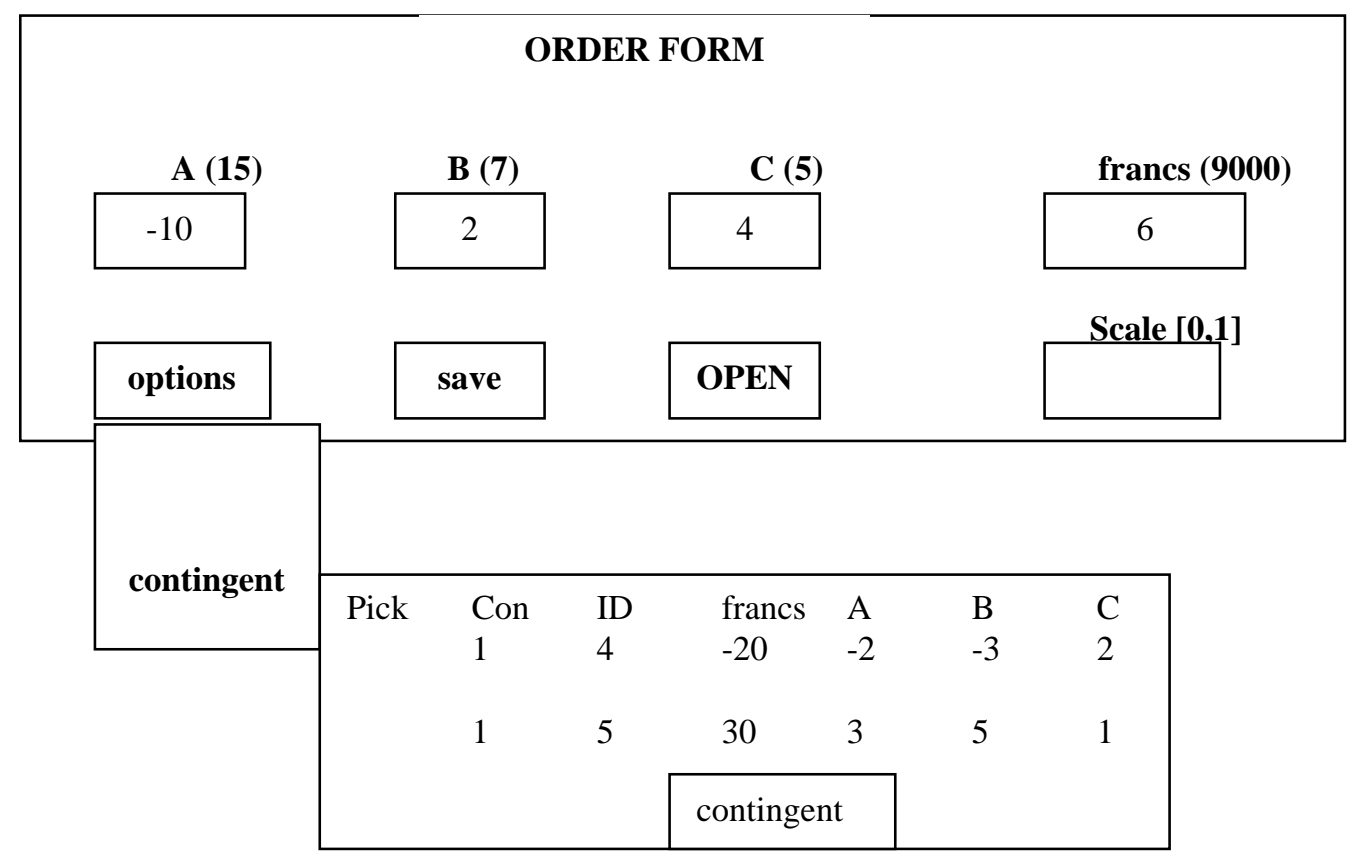

Open Orders Unless you specify otherwise, the orders you submit in a round will be closed, i.e., no other participant can view what you send to the market during the round. If you would like others to see what you send to the market before the round finishes you can send the order to the open book. Orders in the open book can be viewed by all participants and will be part of the orders submitted to the market for the round. 


\section{Order Restrictions}

The following three constraints will be placed on your orders:

-[ Your order can be submitted to the market if it does not violate your credit line and you try to sell more units than you have in your account. The constraint on your orders is cumulative. That is, each time an order is submitted your account is reduced by the amounts in that order. Sells count against the item account and buy offers are subtracted from your franc account. For contingent orders, we will use the maximum amount of each sell item and buy offer among the tied orders to debt your account. However, sell orders do not increase your franc account and buy orders do not increase your unit accounts.

- One other important restriction on the accepted orders in a round is that all transactions will be in whole numbers, i.e., units are transacted in increments of size 1. Thus, all bid amounts must be in integer amounts and all transactions will be made in integer amounts.

-[ Only previous round "accepted" orders and open book orders can be changed (they must have a higher buy price or lower sell price). This will be discussed in more detail later.

\section{ROUND Results}

Orders submitted in a round will be placed into a program that finds which orders are standing for the round using the following rules:

1. The accepted orders do not violate the order parameters.

2. The total amount sold is greater than or equal to the total amount purchased. 
3. The difference between the buy offers and the sell offers from the accepted orders that obey 1 and 2 is as large, net of transaction fees, as we can find. We will call this amount the market surplus.

The set of accepted orders from the above rules become the Standing Orders for the market. Standing orders in a round are automatically submitted to the next round. Participants holding standing orders or open book orders may increase the offer price on the order, and may include the order in a contingent order. Participants can also submit new orders each round.

Market buy prices and market sell prices will be calculated each period. The market price of an order is then (buy prices * amounts bought) - (sell prices * amounts sold). Prices will be chosen, if possible, so that

1. The market buy and market sell prices are the same.

2. The market price of each accepted (rejected) order, is less than (greater than) or equal to its offer amount.

The amount you will pay (receive if the market price is negative) for an accepted order if the market were to close in that round is:

Your Payment=(market buy prices*amounts you buy $)-($ market sell prices*amounts you sell) 


\section{Round Result Information}

When the round ends, we will display aggregate results of the round. Specifically, we will provide participants with the following informational display

\begin{tabular}{|c|c|c|c|c|}
\hline Round & Current Surplus & $\begin{array}{l}\text { Change } \\
\text { in Surplus }\end{array}$ & Total Volume & $\begin{array}{c}\text { Change in Total } \\
\text { Volume }\end{array}$ \\
\hline 3 & 100 & 20 & 10 & 5 \\
\hline & & $\mathrm{A}$ & $\mathrm{B}$ & $\mathrm{C}$ \\
\hline market buy price & & 2 & 1 & 2 \\
\hline market sell price & & 1.5 & .5 & 1.75 \\
\hline units traded & & 3 & 3 & 4 \\
\hline units available & & 10 & 10 & 10 \\
\hline sell units offered & & 5 & 5 & 10 \\
\hline buy units offered & & 10 & 10 & 10 \\
\hline
\end{tabular}

You will also see the orders that you had accepted along with your prices. After the round starts you will be able to see the open book orders.

\section{STOPPING the Period}

The auction period will end after round 2 if surplus or volume does not increase by 5\% over previous round surplus or volume. 


\section{FIGURES}

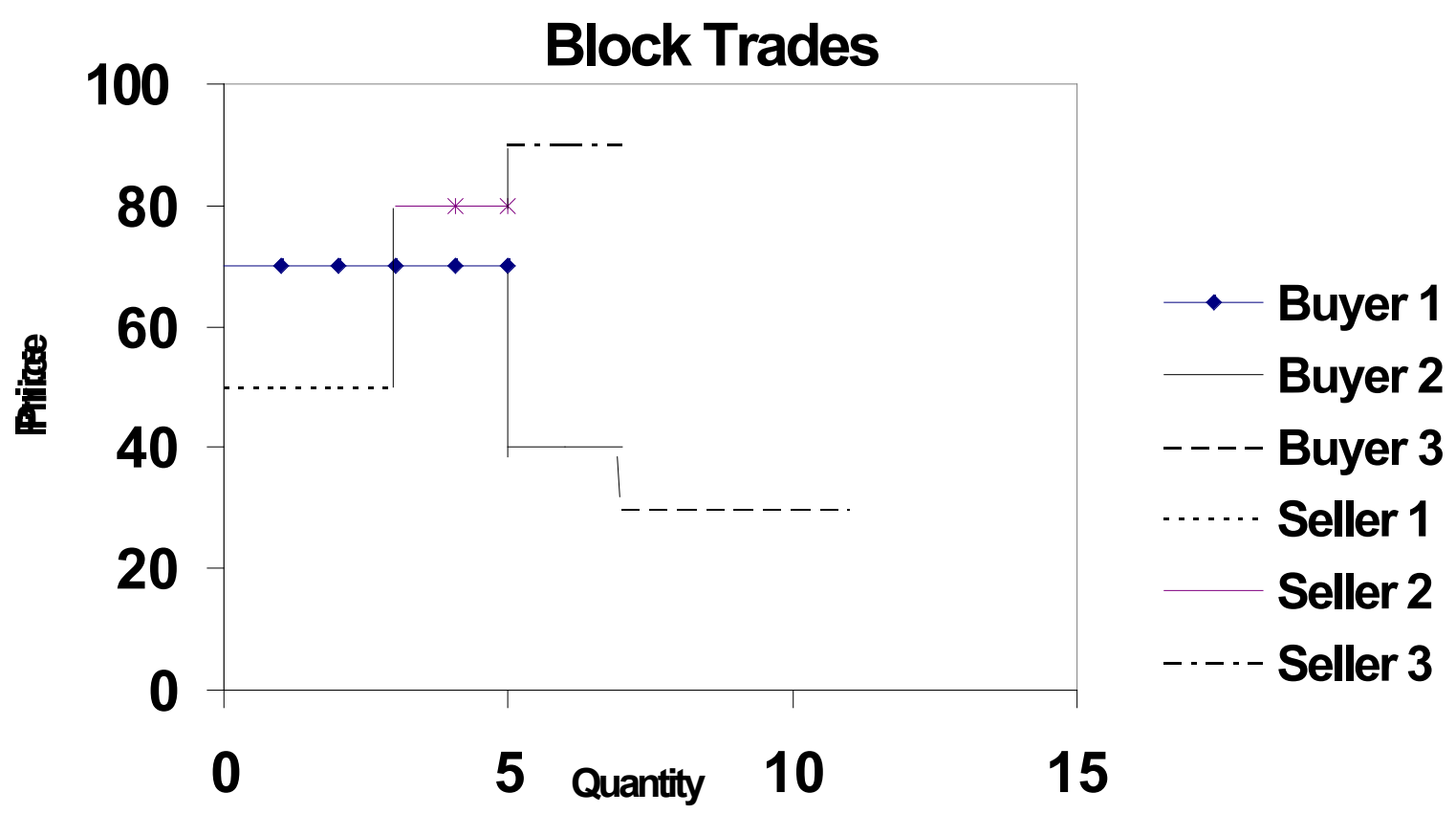

Figure 1: An all or nothing trading example where there is no uniform price equilibrium. 

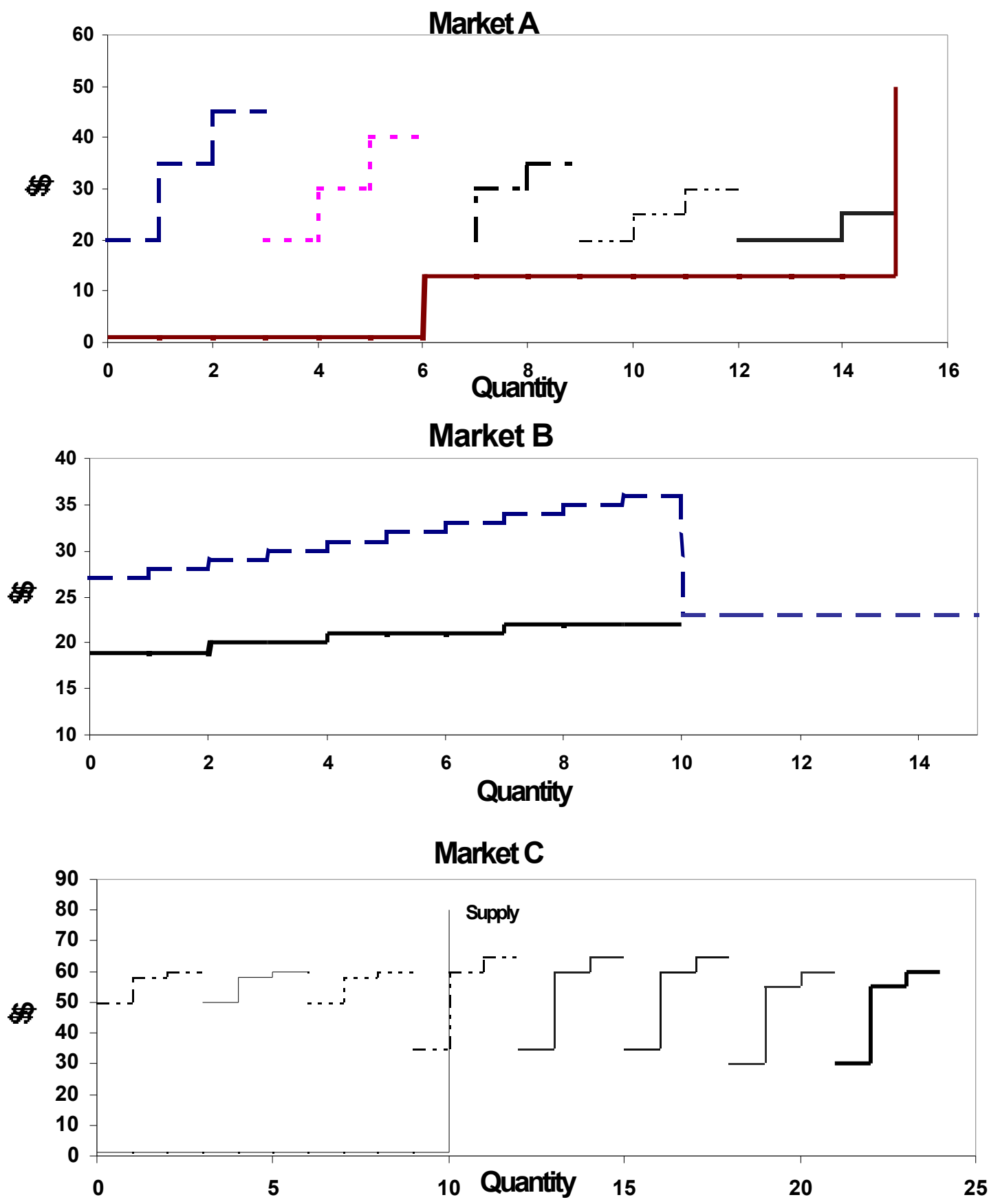

Figure 2: Superadditive valued markets. Markets A and B have a uniform price competitive equilibrium price. Market $\mathrm{C}$ has a nonlinear competitive price equilibrium 

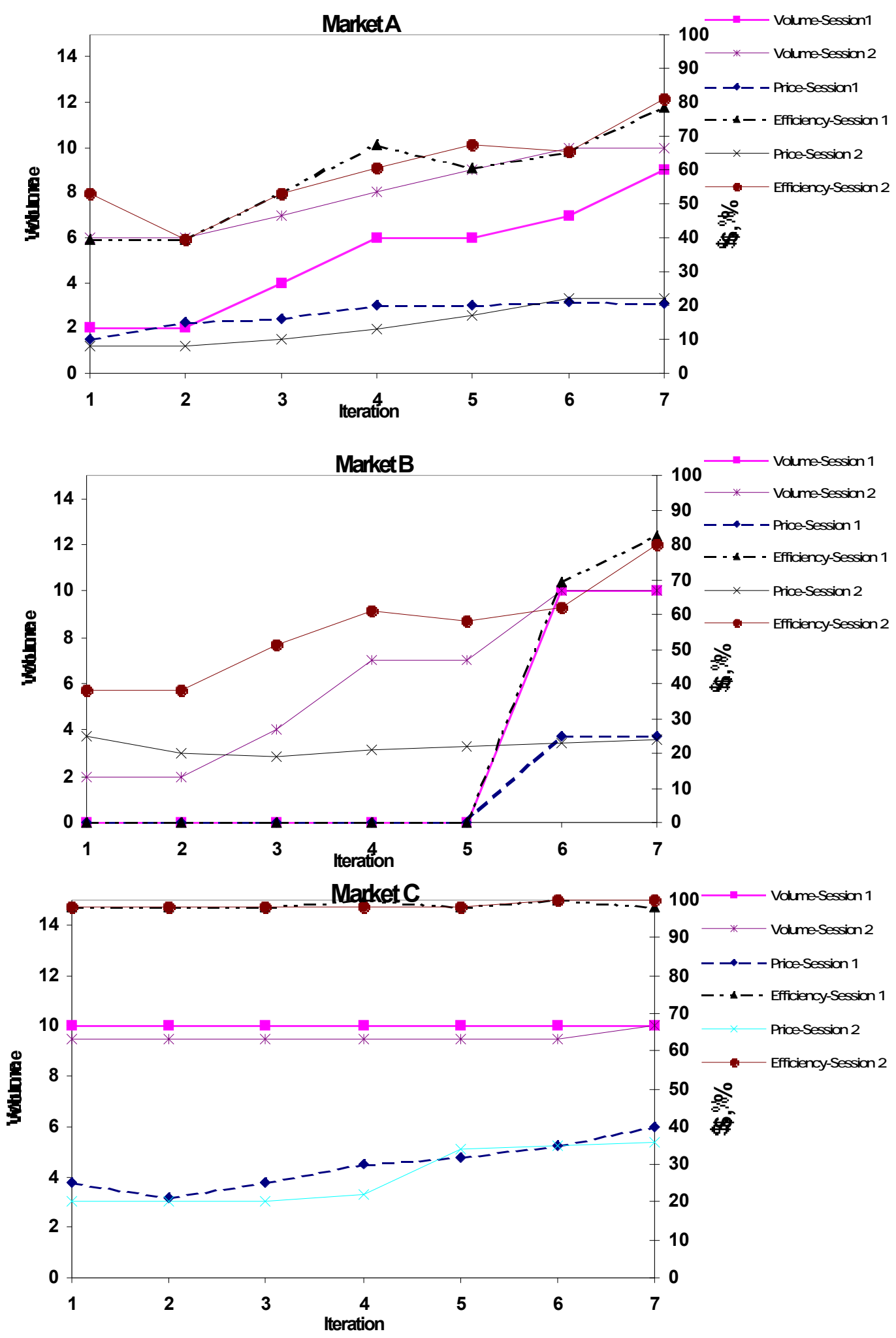

Figure 3: Supperadditive results using UPDA 

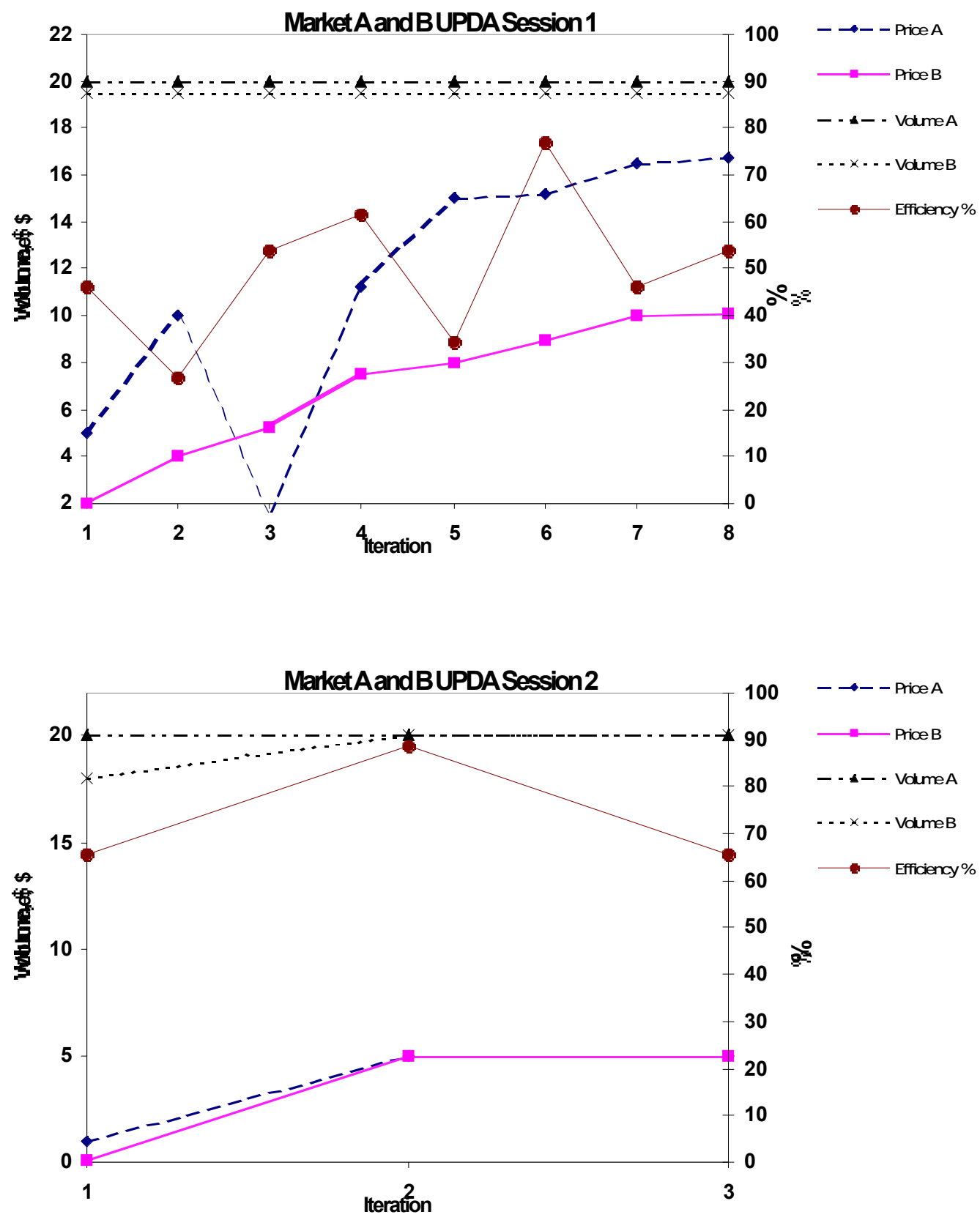

Figure 4: strong complements results using UPDA 


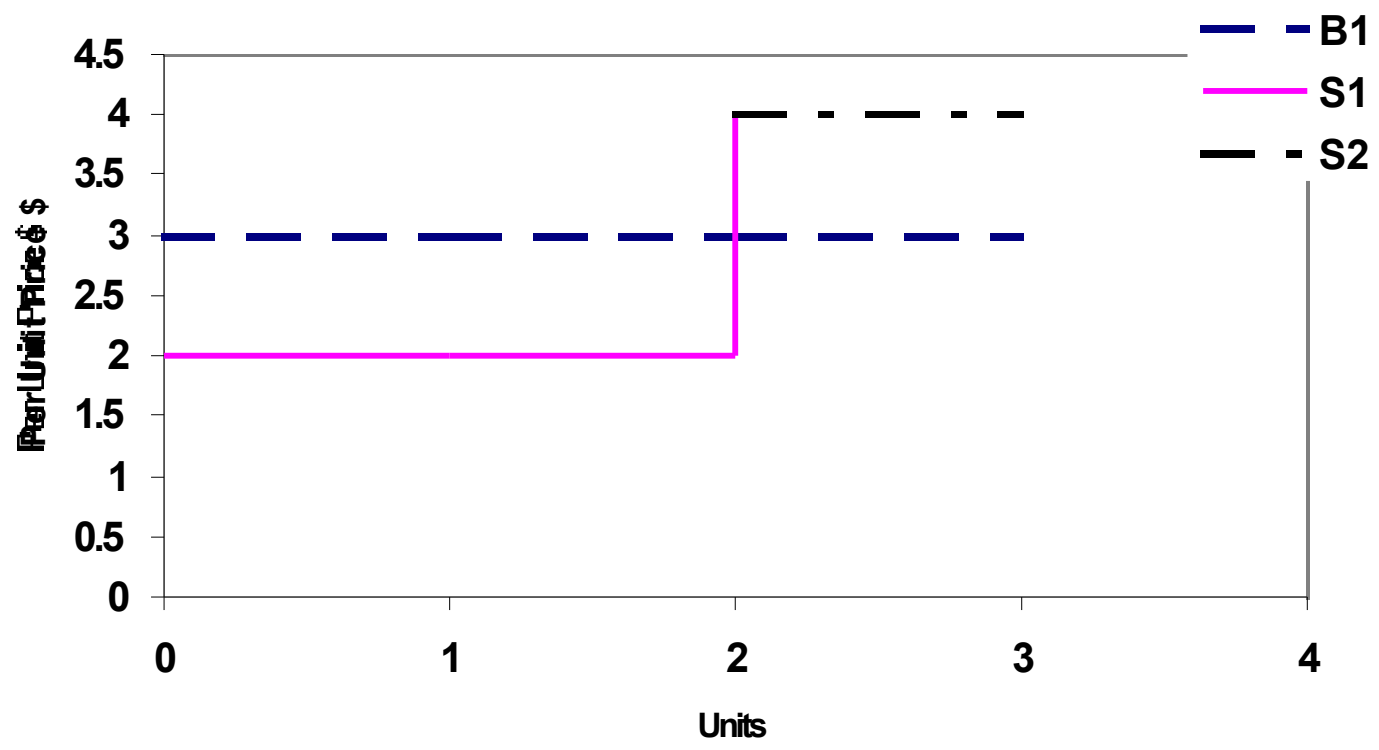

Figure 5: Non-Existence of Equilibrium for All or Nothing Trades

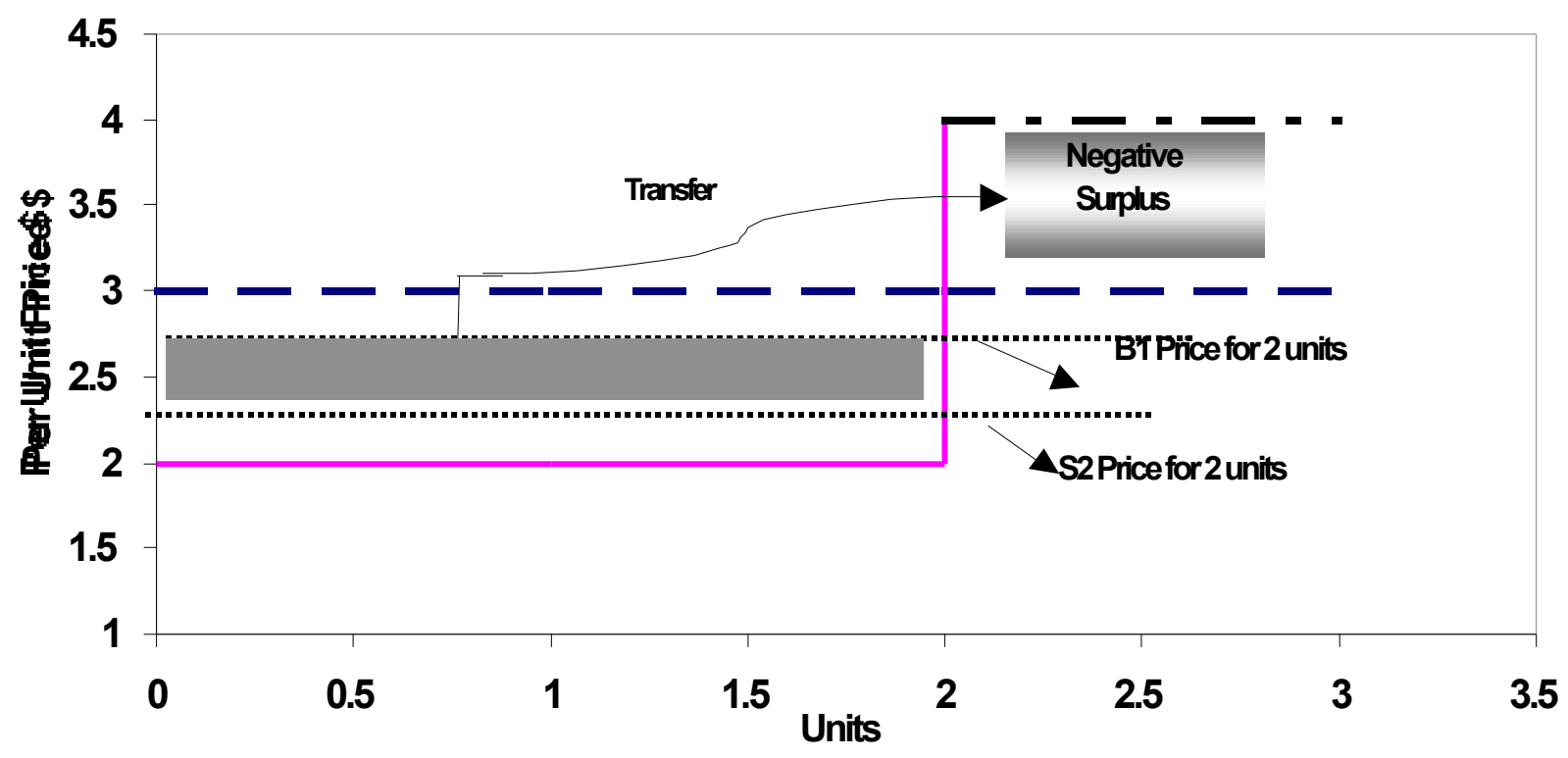

Figure 6: Price Calculation with All or Nothing Orders 


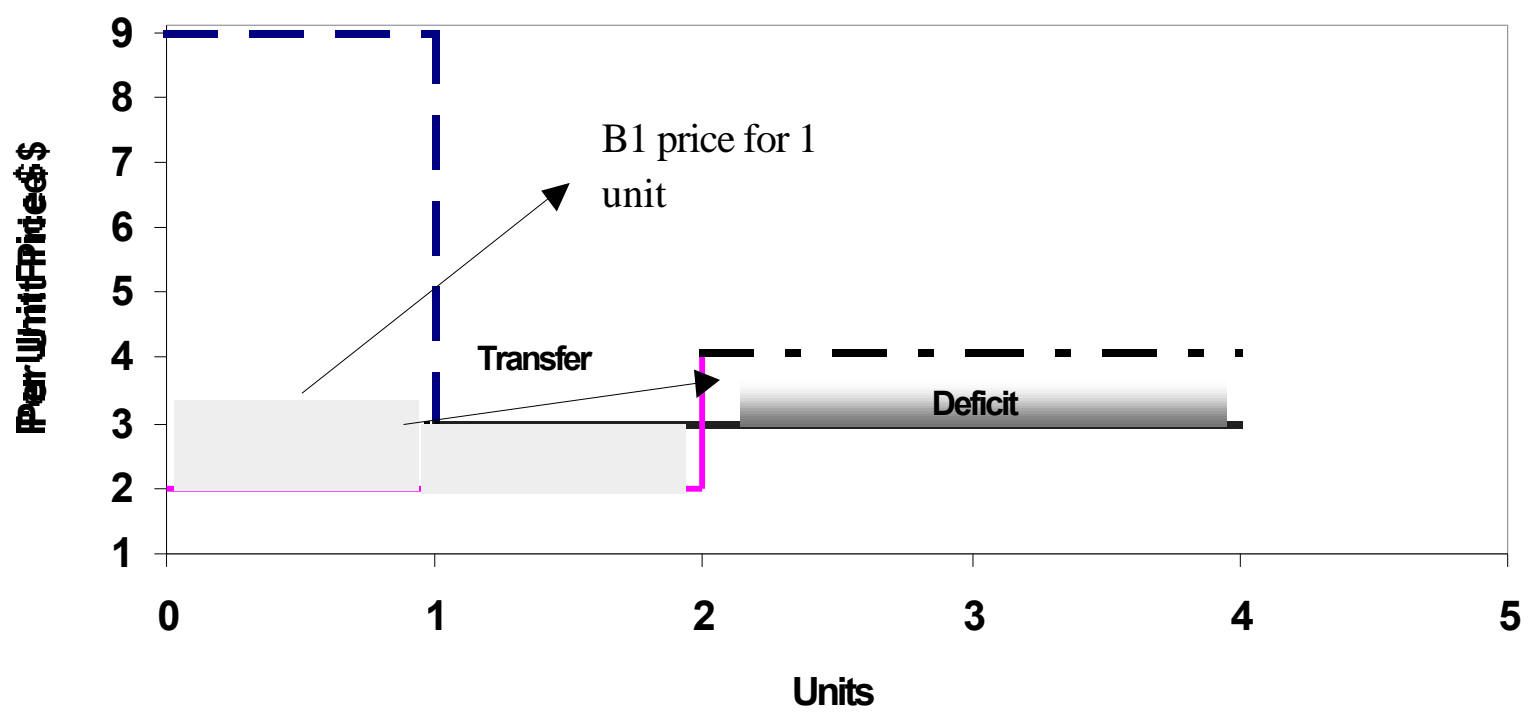

Figure 7: Price Calculation 

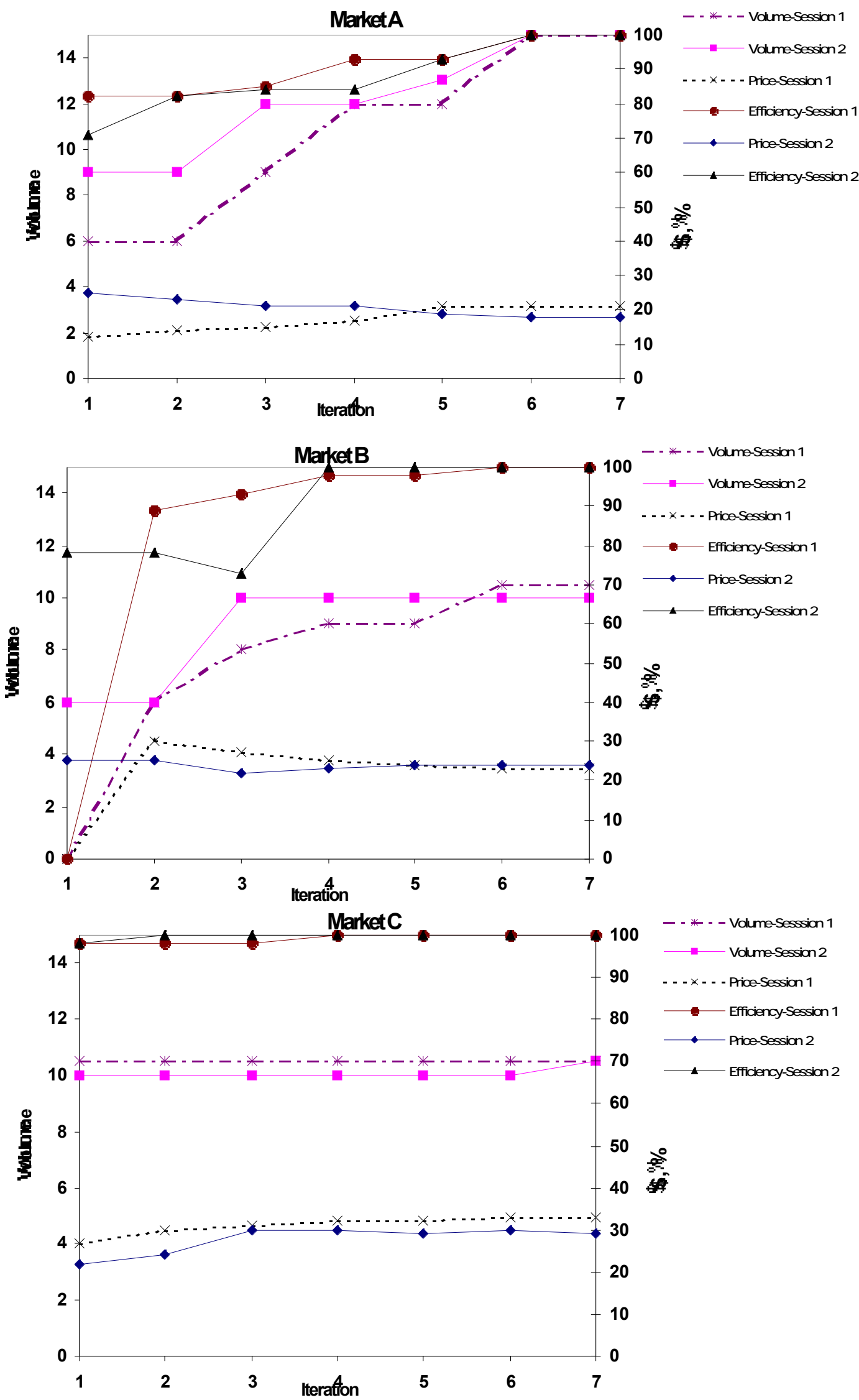

Figure 8: Superadditive results using CVCM 


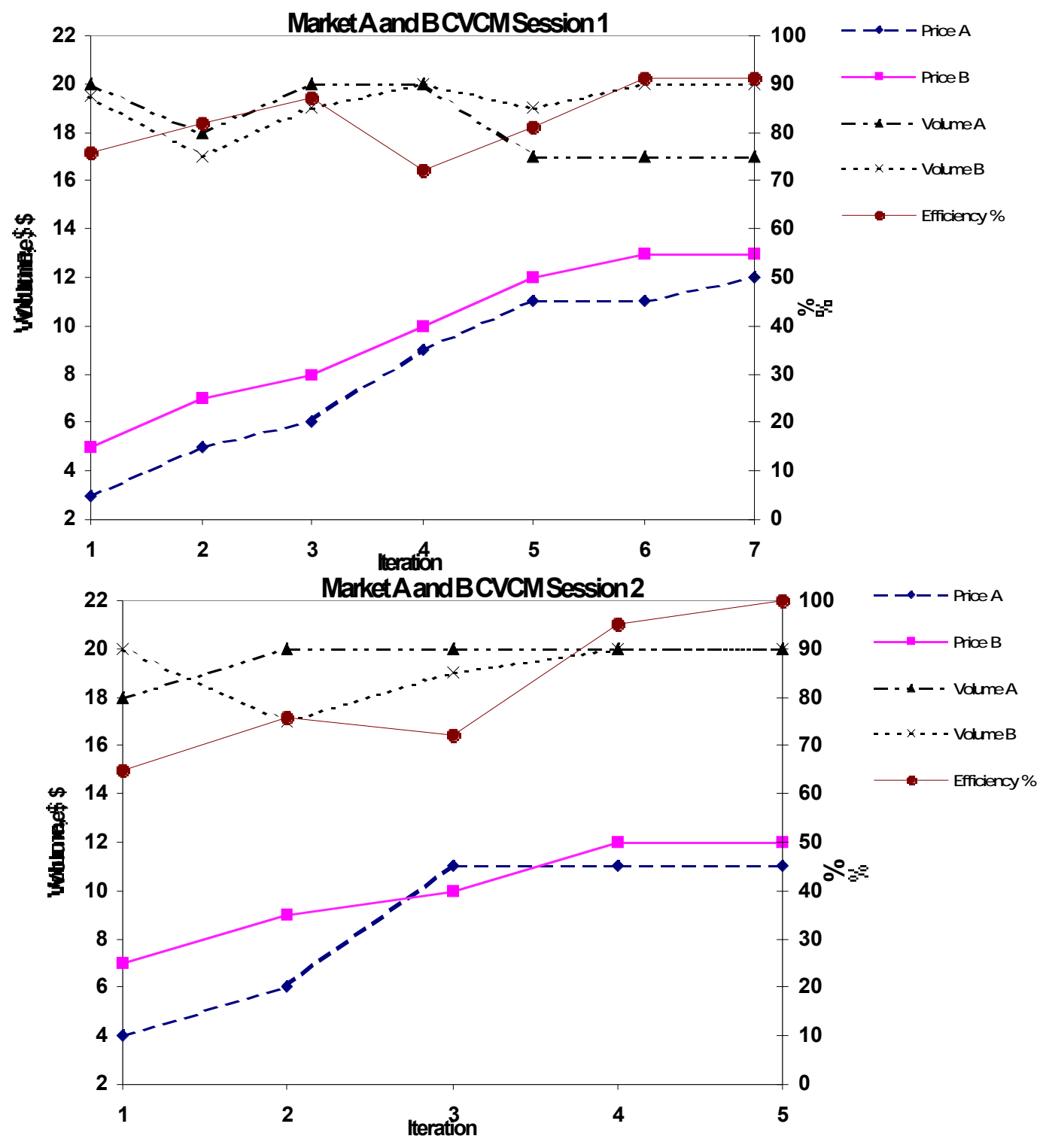

Figure 9: Strong complement results using CVCM 


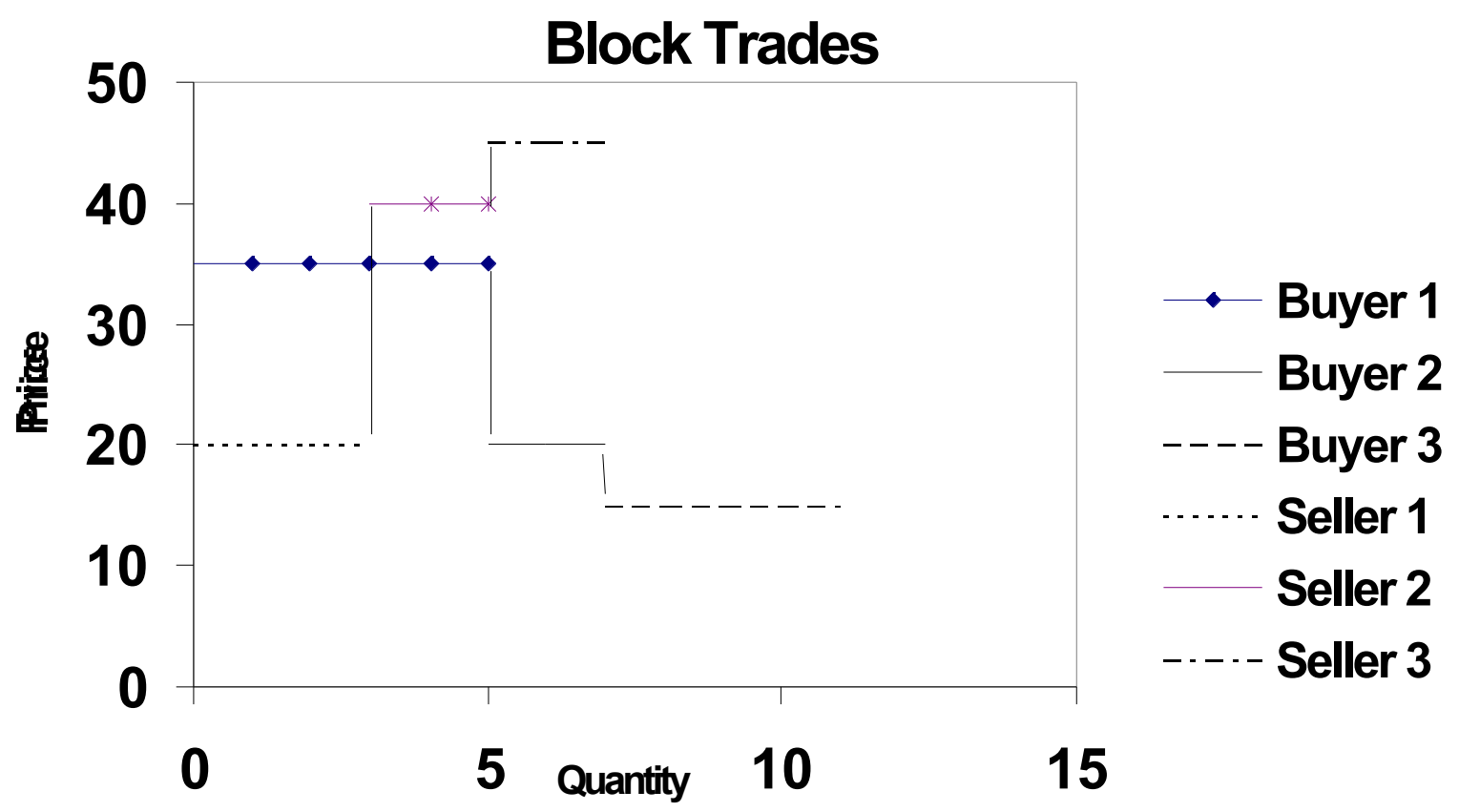

Figure 10: Block Trade Environment 

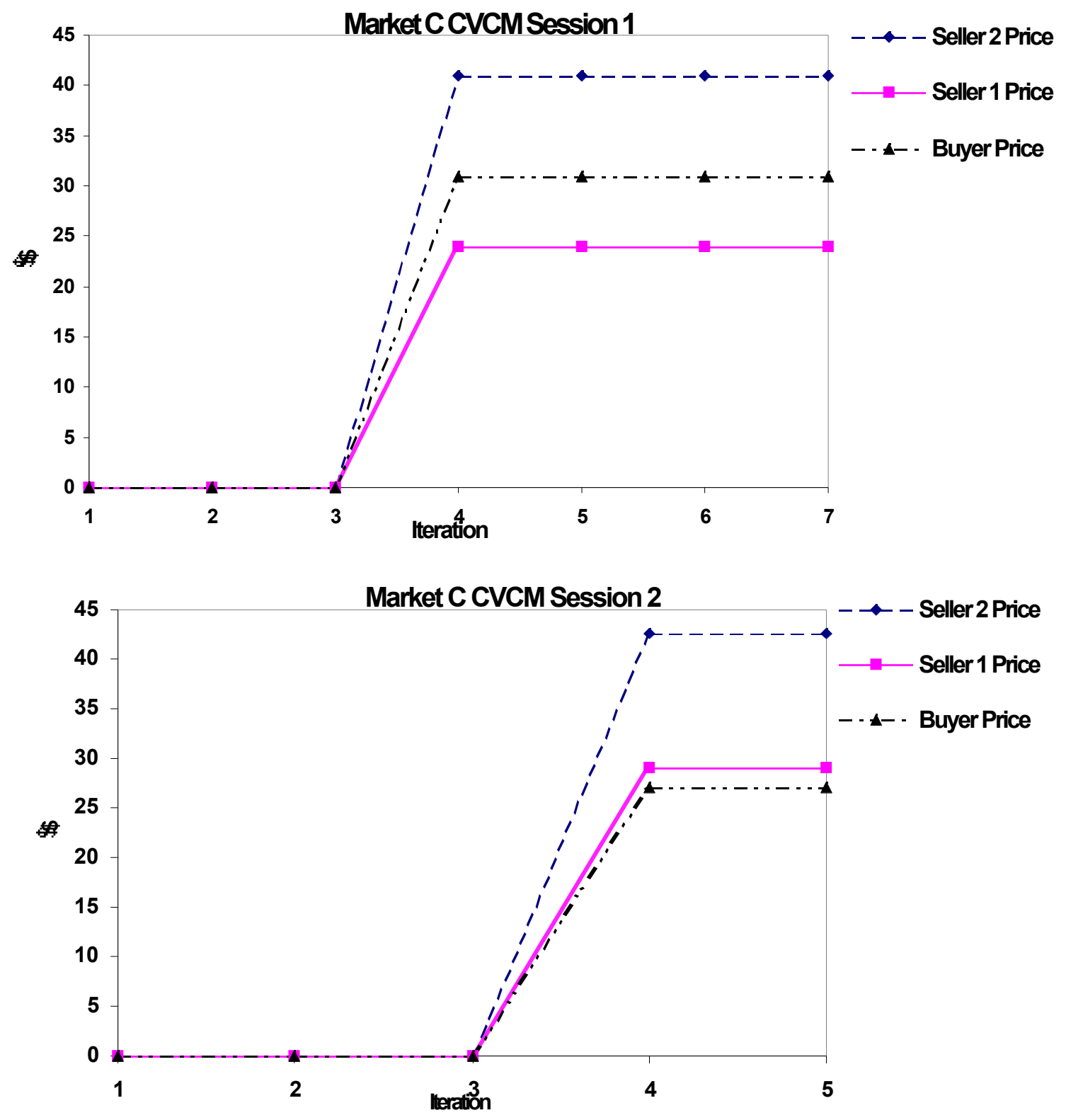

Figure 11: Block Trade Results using CVCM 